\title{
Improved Performance Low-Cost Incremental Conductance PV MPPT Technique
}

\author{
N.E. Zakzouk, M.A.Elsaharty, A.K. Abdelsalam, A.A. Helal \\ Electrical and Control Engineering Department \\ Arab Academy for Science and Technology (AAST) \\ Alexandria, Egypt
}

\author{
B.W. Williams \\ Electronics and Electrical Engineering Department \\ Strathclyde University \\ Glas gow, United Kingdom
}

\begin{abstract}
Variable-step incremental conductance (Inc.Cond.) technique, for photovoltaic (PV) maximum power point tracking (MPPT), has merits of good tracking accuracy and fast convergence speed. Yet, it lacks simplicity in its implementation due to the mathematical division computations involved in its algorithm structure. Furthermore, the conventional variable step-size, based on the division of the PV module power change by the PV voltage change, encounters steady-state power oscillations and dynamic problems especially under sudden environmental changes. In this paper, an enhancement is introduced to Inc.Cond. algorithm in order to entirely eliminate the division calculations involved in its structure. Hence, algorithm implementation complexity is minimized enabling the utilization of low-cost microcontrollers to cut down system cost. Moreover, the required real processing time is reduced, thus sampling rate can be improved to fasten system response during sudden changes. Regarding the applied step-size, a modified variable-step size, which depends solely on PV power, is proposed. The latter achieves enhanced transient performance with minimal steady-state power oscillations around the MPP even under partial shading. For proposed technique's validation, simulation work is carried out and an experimental set up is implemented in which ARDUINO Uno board, based on low-cost Atmega328 microcontroller, is employed.
\end{abstract}

Keywords-PV module, MPPT, incremental conductance, variable step size, environmental changes, low-cost microcontroller, and partial shading.

\section{Introduction}

The modern industrial society, population growth, and the interest in the environmental issues have greatly increased the need of new and clean renewable energy sources [1]. Among the latter, Photovoltaic (PV) solar energy has become nowadays a real promising renewable/ alternate energy source due to its several advantages such as; absence of noise or mechanical moving parts, low operation cost, no emission of $\mathrm{CO}_{2}$ or other harmful gases, flexibility in size, and its convenience with stand-alone systems in addition to grid-connected ones where they can be installed close to load centres, saving transmission lines losses [2-3]. Although PV energy has recently received considerable attention, high installation cost and low conversion efficiency of PV systems set a difficulty against its use on a large scale [4]. Furthermore, the non-linear behaviour and dependency of PV panels on the atmospheric temperature and irradiance level create one of the main challenges facing the PV sector's penetration to the energy market [5]. To minimize these drawbacks, PV operation at the maximum power point is a necessity which in turn maximizes the PV system 
efficiency. Various MPPT techniques have been presented in literature [6-9].They differ in the tracking accuracy, convergence speed, dynamic response under sudden environmental changes, required sensors, hardware implementation, and dependency on PV module parameters.

The most commonly used MPPT algorithms are perturb and observe (P\&O) and incremental conductance (Inc.Cond.) methods [10]. P\&O algorithm is widely used in PV stand-alone systems for its simple implementation [11-14]. In these PV systems, MPPT algorithms are preferably realized using low cost microcontrollers in order to cut down the entire system cost. Thus, the P\&O, being an arithmetic-division-free algorithm, is a convenient choice to be implemented by these controllers. On the other hand, Inc.Cond. is more complex in structure than $\mathrm{P} \& \mathrm{O}$ as it inhibits many mathematical divisions which increase the computational burden [15]. However, regarding these techniques performance, $\mathrm{P} \& \mathrm{O}$ can easily lead to erroneous judgment and oscillation around the maximum power point (MPP) which results in power loss [16]. Hence, Inc.Cond. technique is a better candidate especially during rapidly varying environmental conditions. This is because, when compared to P\&O method, Inc.Cond. can accurately track the MPP, with less steadystate oscillations and faster response during changes thus increasing the tracking efficiency [17-21].

In addition, many modifications have been introduced to fixed step-size used in the Inc.Cond. method to change it to a variable one that gets smaller towards the MPP [22-28]. The latter improves the technique performance and solves the trade-off between tracking accuracy and convergence speed. However, conventional variable step-size, automatically adjusted according to the PV power change with respect to PV voltage change $(\Delta P / \Delta V)$, can affect the MPPT performance due to the digression of this step size, particularly under sudden changes [29, 30].

This paper aims at combining the advantages of simple algorithm structure with high system performance during transients in one MPPT technique. Hence, a modified Inc.Cond. algorithm is proposed featuring full elimination of the division calculations thus, simplifying the algorithm structure. In addition, a variable step-size is proposed which only depends on the PV power change $(\Delta P)$, thus eliminating its division by the PV voltage change $(\Delta V)$. The proposed step-size can minimize power oscillations around the MPP and effectively improve the MPPT dynamics during sudden changes. This will result in a total division-free variable-step technique which does not only have the merits of enhanced steady-state and transient performance but also has simple algorithm implementation. This reduces the processing real-time, enabling the algorithm to be implemented by low-cost microcontrollers which in turn reduces system costs.

This paper is organized in eight sections. Following the introduction, the investigated PV system is presented. The following two sections explain the conventional and the proposed Inc.Cond. techniques regarding their algorithm structure and the applied variable step-size. The simulation and experimental results, which verify the superiority of the proposed technique over the conventional one, are illustrated in the fifth and sixth sections respectively. An assessment is performed for the proposed MPPT technique under partial shading conditions in the seventh section. Finally, a conclusion is presented in the eighth section. 


\section{PV system under investigation}

The considered PV system consists of a PV module, a DC-DC boost converter and a battery load as shown in fig. 1(a).

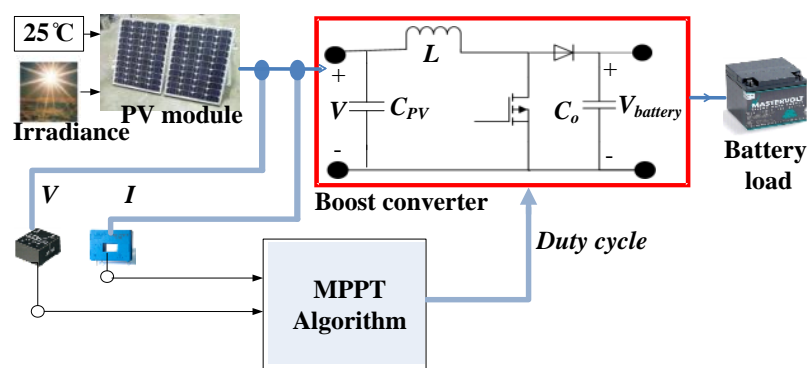

(a)

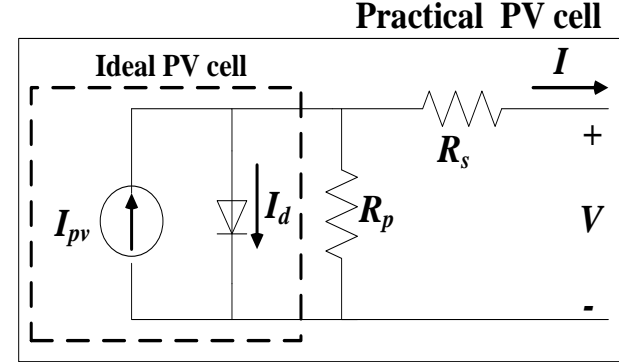

(b)

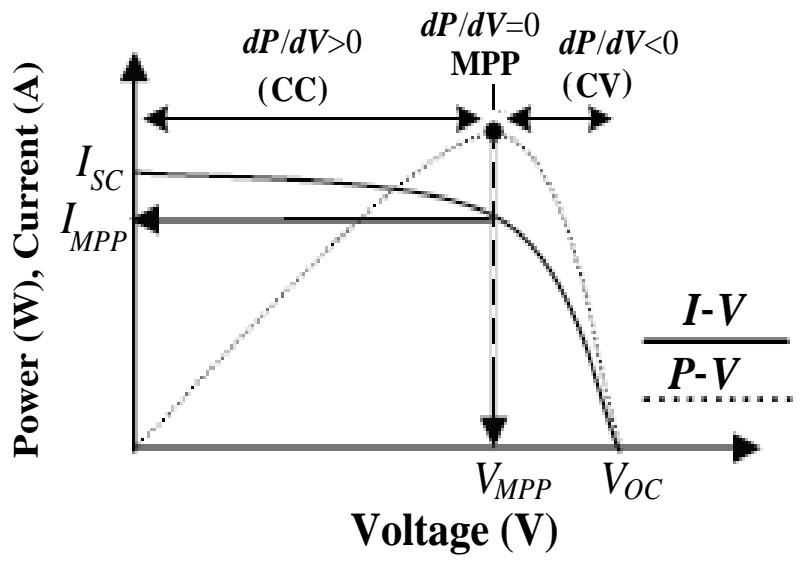

(c)

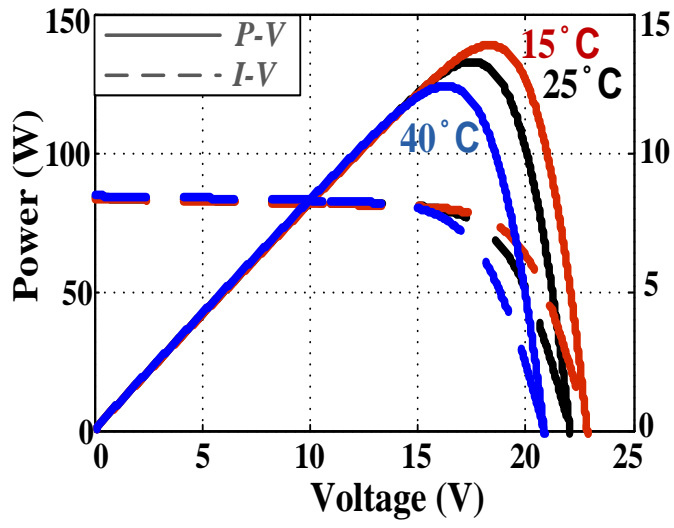

(d)

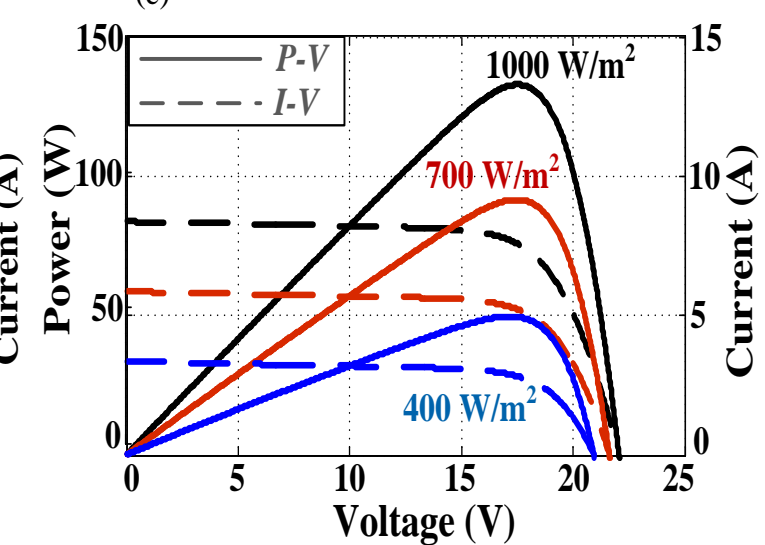

(e)

Fig. 1: PV system under consideration (a) Schematic diagram, (b) $\mathrm{PV}$ cell single diode model, (c) $I-V$ and $P$ - $V$ characteristics at given conditions, $I-V$ and $P-V$ curves of KD135SX_UPU PV module: (d) under three irradiance levels at $25^{\circ} \mathrm{C}$ and (e) for three different cell temperatures at irradiance of $1000 \mathrm{~W} / \mathrm{m}^{2}$

\section{A. PV mathematical model}

A practical PV device can be represented by a light-generated current source and a diode altogether with internal shunt and series resistances as shown in fig. 1(b). A PV module is composed of several PV cells and the observation of the characteristics at its terminals results in expressing its output current by the following equation [31];

$I=I_{p v}-I_{o}\left[\exp \left(\frac{V+R_{s} I}{V_{t} a}\right)-1\right]-\frac{V+R_{s} I}{R_{p}}$ 
where $V$ and $I$ are the PV output voltage and current respectively. $I_{p v}$ is the photovoltaic current which is generated by the incident light (directly proportional to the sun irradiance) and $I_{o}$ is the saturation current of the PV module. $a$ is the diode ideality constant and $R_{s}, R_{p}$ are the internal series and parallel resistances of the module respectively. Finally, $V_{\mathrm{t}}$ is the PV thermal voltage with $N_{\mathrm{s}} \mathrm{PV}$ cells connected in series. $V_{t}$ equals to $N_{\mathrm{s}} k T / q$ where; $q$ is the electron charge $\left(1.60217646 \times 10^{-19} \mathrm{C}\right), k$ is Boltzmann constant $\left(1.3806503 \times 10-23 \mathrm{~J} /{ }^{\circ} \mathrm{K}\right)$, and $T\left(\right.$ in $\left.{ }^{\circ} \mathrm{K}\right)$ is the temperature of the $p-n$ junction.

\section{B. Boost converter}

The design of boost converter, shown in fig. 1, can be summarized as follows [32];

$$
\begin{aligned}
& V=V_{\text {battery }}(1-D) \\
& \Delta i_{L}=\frac{V D}{L f_{s w}}
\end{aligned}
$$

where $V$ is the PV output voltage, $V_{\text {battery }}$ is the battery load voltage and $D$ is the duty ratio determined by the applied MPPT algorithm to directly control the boost chopper switching. $\Delta i_{L}$ is the change in inductor current, $L$ is the chopper inductor and $f_{s w}$ is the chopper switching frequency.

\section{C. $M P P T$}

Equation (1) shows that a PV module has non-linear I-V characteristics that depend on the irradiance level and PV cells' temperature. Fig. 1(c) shows the $I-V$ and $P-V$ curves of a PV module, at a given cell temperature and irradiance level, on which it's noticeable that the PV panel has an optimal operating point, the maximum power point (MPP). In the region left to the MPP, the PV current is almost constant and the PV module can be approximated as a constant current (CC) source. On the other hand, right to the MPP, the PV current begins a sharp decline and the PV module can be approximated as a constant voltage (CV) source. The PV module characteristic curves vary with the changing irradiance level and cell temperature [5], as shown in fig. 1 parts (d) and (e). The PV module short-circuit current is linearly dependent on the irradiance level unlike the open-circuit voltage which almost independent of it. On the other hand, PV cell temperature significantly affects the open-circuit voltage value whereas it has a negligible effect on the short circuit current value.

As the PV module characteristic curve shifts with changing irradiance or cell temperature, the MPP moves. Hence, continuous tracking to the MPP becomes mandatory to maximize the PV system efficiency. The latter is achieved using an MPPT algorithm which determines the appropriate duty ratio $(D)$ that controls the switching of the DC-DC converter placed between the PV module and the load to ensure that the PV panel maximum power is extracted. A successful MPPT technique compromises between the tracking speed and steady-state accuracy and shows fast response during sudden environmental changes. According to these criteria, the Inc.Cond. technique can be considered as an appropriate candidate [17-21]. 


\section{Conventional variable-step incremental conductance technique}

The structure of the conventional variable-step Inc.Cond. technique can be illustrated in the following two subsections;

A. Conventional Inc.Cond. algorithm

Inc.Cond. technique is based on the slope of the PV module $P$ - $V$ curve [6] where;

$\frac{d P}{d V}=0 \quad$ at MPP

$\frac{d P}{d V}>0 \quad$ left to MPP

$\frac{d P}{d V}<0 \quad$ right to MPP

Since

$\frac{d P}{d V}=\frac{d(I V)}{d V}=I+V \frac{d I}{d V} \cong I+V \frac{\Delta I}{\Delta V}$

Then

$\begin{array}{ll}\frac{\Delta I}{\Delta V}=\frac{-I}{V} & \text { at MPP } \\ \frac{\Delta I}{\Delta V}>\frac{-I}{V} & \text { left to MPP } \\ \frac{\Delta I}{\Delta V}<\frac{-I}{V} & \text { right to MPP }\end{array}$

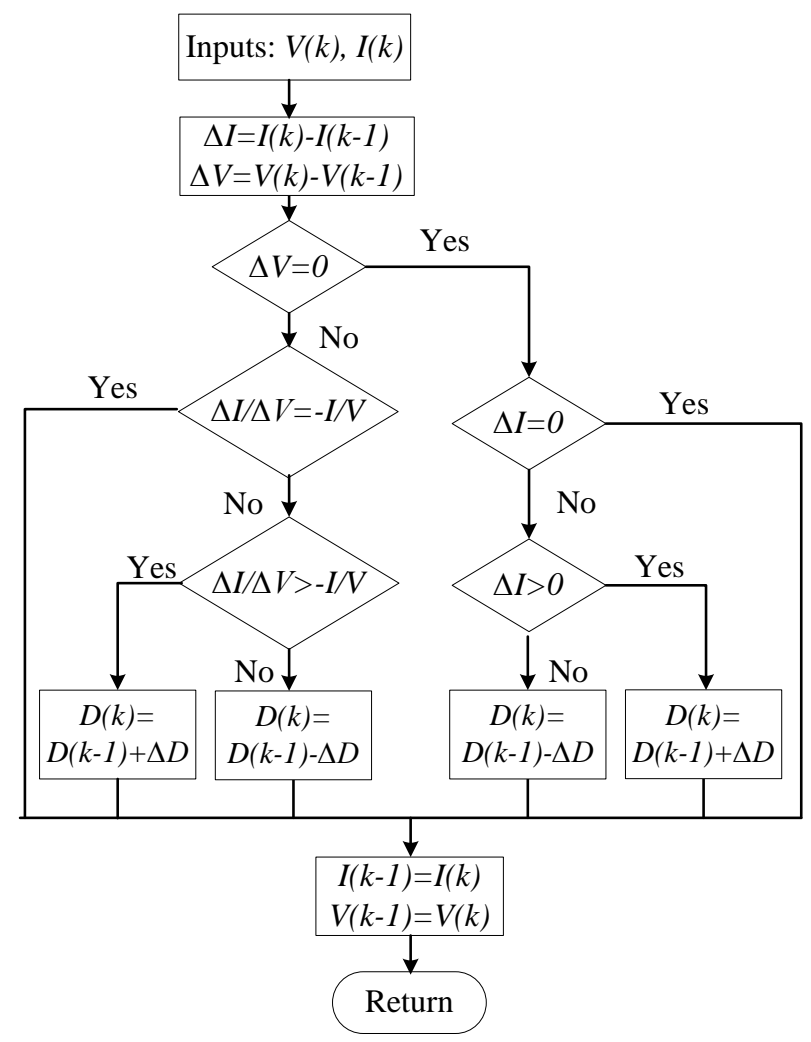

Fig. 2: Inc.Cond. algorithm flowchart (a) conventional 
The MPP can thus be tracked by comparing the instantaneous conductance $(I / V)$ to the incremental conductance $(\Delta I / \Delta V)$ and accordingly the voltage perturbation sign is determined till reaching the MPP [7]. The flowchart of the conventional Inc.Cond. algorithm is shown in fig. 2(a). If the irradiance increases (decreases) i.e. PV current increases (decreases), the MPP moves to the right (left) with respect to PV voltage. To compensate for this movement, the MPPT must increase (decrease) the PV module's operating voltage.

When compared to other simple, low cost MPPT algorithms as P\&O [12], the main advantage of Inc.Cond. algorithm is that it can determine the accurate direction to reach the MPP thus decreasing the steady-state oscillations and improving system response under rapidly changing conditions [16-21]. However, regarding the algorithm structure, conventional Inc.Cond. algorithm includes a number of division calculations and a relatively complex decision making process which in turn raises the need of a more powerful microcontroller featuring higher clock frequency, larger memory and floating-point calculation capability, decreasing the possibility of achieving a low cost system solution [15].

\section{B. Conventional variable step-size}

For a fixed-step Inc.Cond. algorithm, a smaller step-size slows down the MPPT while a larger one increases the steady-state oscillations around the MPP. A solution to this conflicting situation is to have a variable step-size that gets smaller towards the MPP in order to balance the competing aims of convergence speed and tracking accuracy. The conventional variable step-size depends on the PV power change divided by the PV voltage change $(\Delta P / \Delta V)[23]$. For a direct control scheme which directly controls the converter switching without external control loops, the considered step is the change in the converter duty ratio $(\Delta D)$ as shown in (11).

$$
\Delta D(\text { conv. })=N_{1}\left|\frac{\Delta P}{\Delta V}\right|
$$

where;

$\Delta P=P(k)-P(k-1)$

$\Delta V=V(k)-V(k-1)$

$\Delta D=D(k)-D(k-1)$

and $N_{l}$ is the scaling factor tuned at the design stage to adjust the conventional step-size $(\Delta D)$ to compromise between tracking accuracy and its convergence speed.

\section{Proposed variable-step incremental conductance technique}

An enhancement is introduced in the structure of the conventional Inc.Cond. algorithm to eliminate all its division computations and simplify its implementation. Moreover, the conventional variable step is modified to improve its performance. The proposed step size is used by the proposed division-free Inc.Cond. algorithm to directly control the converter switching. 


\section{A. Proposed division-free Inc.Cond. algorithm}

A modification is introduced to the Inc.Cond. algorithm in order to eliminate all the division computations in the algorithm. Using

(8) - (10), the following modifications can be implemented:

$\frac{\Delta I}{\Delta V}+\frac{I}{V}=0$

at MPP

$\frac{\Delta I}{\Delta V}+\frac{I}{V}>0 \quad$ left to MPP

$\frac{\Delta I}{\Delta V}+\frac{I}{V}<0 \quad$ right to MPP

Unifying the denominators in (15) - (17) to $V(\Delta V)$, this denominator can be eliminated from the first equation as it is equalized to zero whereas only $V$ is eliminated from the denominator of the other two equations as it is always positive and its sign won't affect these equations. Thus, manipulating (18) - (20) results in;

$$
\begin{array}{cr}
(V \bullet \Delta I)+(I \bullet \Delta V)=0 & \text { at MPP } \\
\frac{(V \bullet \Delta I)+(I \bullet \Delta V)}{\Delta V}>0 & \text { left to MPP } \\
\frac{(V \bullet \Delta I)+(I \bullet \Delta V)}{\Delta V}<0 & \text { right to MPP }
\end{array}
$$

Finally, in order to eliminate the division calculations, the Inc.Cond. algorithm rules can be rewritten as follows:

$$
\begin{aligned}
& (\boldsymbol{V} \bullet \Delta \boldsymbol{I})+(\boldsymbol{I} \bullet \Delta \boldsymbol{V})=\mathbf{0} \quad \text { at MPP } \\
& (\boldsymbol{V} \bullet \Delta \boldsymbol{I})+(\boldsymbol{I} \bullet \Delta \boldsymbol{V})>0 \quad \& \& \Delta \boldsymbol{V}>0 \quad \text { left to MPP } \\
& (\boldsymbol{V} \bullet \Delta \boldsymbol{I})+(\boldsymbol{I} \bullet \Delta \boldsymbol{V})>0 \quad \& \& \Delta \boldsymbol{V}<0 \quad \text { right to MPP } \\
& (\boldsymbol{V} \bullet \Delta \boldsymbol{I})+(\boldsymbol{I} \bullet \Delta \boldsymbol{V})<0 \quad \& \& \Delta \boldsymbol{V}>0 \quad \text { right to MPP } \\
& (\boldsymbol{V} \bullet \Delta \boldsymbol{I})+(\boldsymbol{I} \bullet \Delta \boldsymbol{V})<0 \quad \& \& \Delta \boldsymbol{V}<0 \quad \text { left to MPP }
\end{aligned}
$$




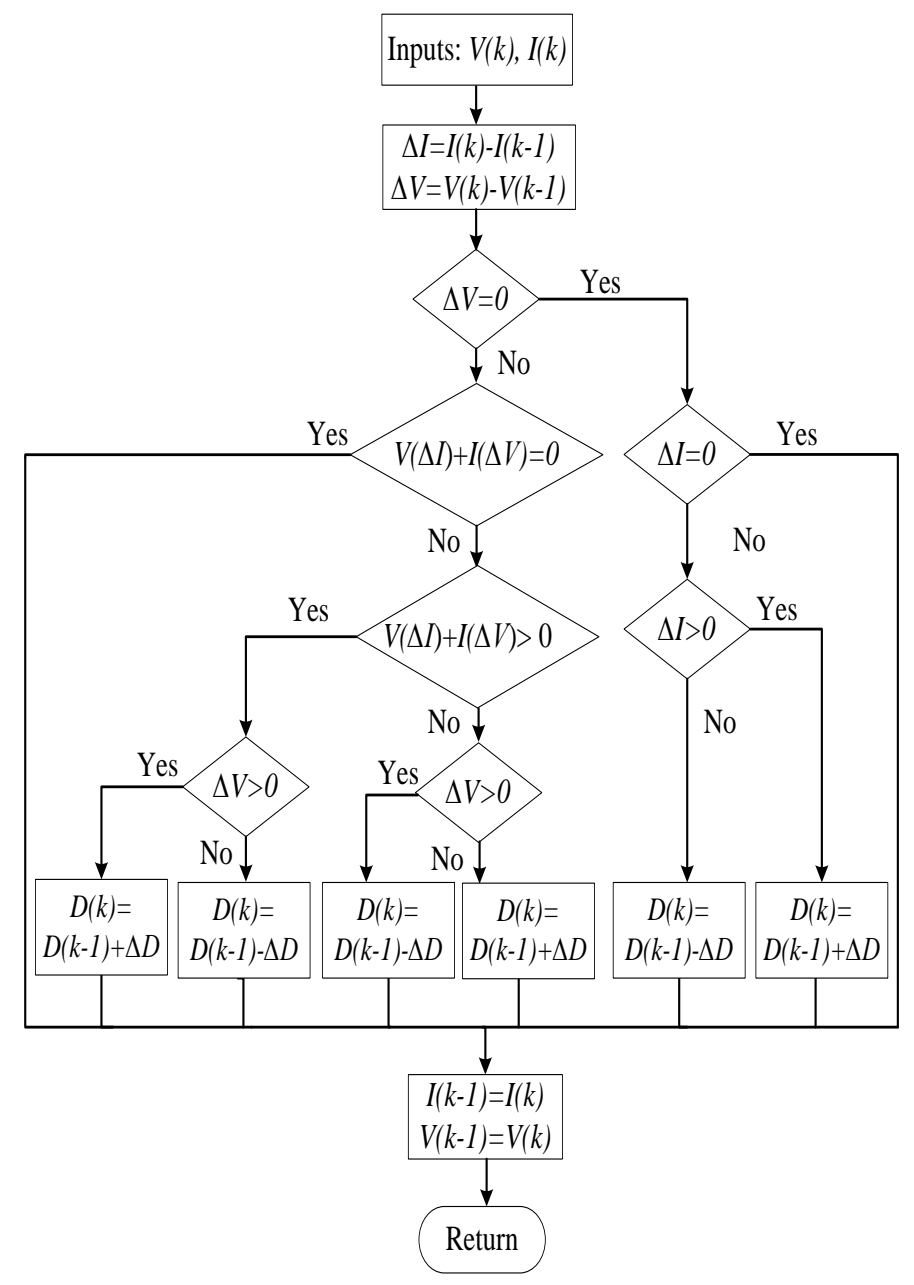

Fig. 2: Inc.Cond. algorithm flowchart (b) proposed

I he flowchart of the proposed algorithm is given in $\mathrm{t1g}$. 2(b) where the removal of all the division computations in the algorithm is compensated by applying arithmetic/logic mathematical operations. Thus, algorithm structure complexity is minimized which in turn reduces processing real-time and enables the algorithm to be implemented by low cost microcontrollers.

\section{B. Proposed variable step-size}

The conventional step-size presented in (11), being dependant on the change of the PV power with respect to PV voltage change, exhibits dynamic performance deterioration during sudden irradiance changes. Furthermore, steady-state power oscillations noticeably arise around the MPP. This can be explained as follows;

\section{$\underline{\text { During stable environmental conditions }}$}

Because of unavoidable factors as measurement error, ripples and noise, the condition that $(\Delta I / \Delta V)$ and (- $I / V)$ to be exactly equal would never be satisfied. Thus, the operating point won't settle exactly at the MPP. Instead, it oscillates around the MPP, changing the sign of the increment after each $\triangle P$ measurement $[19,20]$. It's clear, from fig. 3(a), that in the regions close to the MPP and right to it (constant voltage region), the change in PV voltage $(\Delta V)$ is too small resulting in large $\Delta P / \Delta V$ steps. Although, these large stepsizes increase the tracking speed at start of PV operation, they can enlarge the steady-state power oscillations affecting the PV system accuracy which in turn decreases the algorithm efficiency. 


\section{During varying irradiance conditions}

The conventional variable step may show poor transient performance during sudden irradiance changes. As shown in fig. 3(a), when the irradiance changes from $\mathrm{G}_{1}$ to $\mathrm{G}_{2}$, there is a considerable power change $(\Delta P)$ while the PV voltage change $(\Delta V)$ is relatively too small. Since the step-size depends on $\Delta P / \Delta V$, this will result in a large converter duty ratio change $(\Delta D)$ thus shifting the operating point far away from the new MPP. Noticeable transient decrease in the PV power occurs and the algorithm takes longer time to reach the new MPP. Consequently, the transient power loss will increase, decreasing the tracking efficiency.

In order to overcome the latter, this paper proposes a variable step-size which depends only on the PV power change $(\Delta P)$. The proposed step size is used by the MPPT algorithm to directly control the converter switching, thus it represent the change in the converter duty ratio as shown in (26);

$$
\Delta D(\text { prop. })=N_{2}|\Delta P|
$$

where $\mathrm{N}_{2}$ is the scaling factor which is tuned at the design stage to adjust the proposed step-size to compromise between the tracking accuracy and its convergence speed.

It's observable, from the PV module $P-V$ curve, that the change in PV power $(\Delta P)$ is small around the MPP and large away from it. Thus, the step-size, which depends on $\Delta P$, will be large away from the MPP and decreases around the MPP to compromise between the steady-state power oscillations and the tracking speed. Unlike the conventional variable step which depends on two rippled parameters $(\Delta P$ and $\Delta V$ ) and their division, the proposed variable step depends only on $\Delta P$. Removing the division by $\Delta V$, from the step-size, adds more simplification to the algorithm and eliminates large step-size variations that occur at small PV voltage changes. Although this may slow down the tracking process at the starting of operation, it minimizes the steady-state oscillations around the MPP thus improving the tracking accuracy and efficiency. Furthermore, this reduces the shift of the operating point away from the MPP during sudden irradiance changes which results in better transient performance with fast dynamic response and less transient power loss.

For further explanation, an illustrative example is shown in fig. 3 parts (b) and (c). When the irradiance decreases from $\mathrm{G}_{1}$ to $\mathrm{G}_{2}$, the operating point shifts from ' $\mathbf{A}$ ' to ' $\mathbf{B}$ ', resulting in a considerable $\Delta P$ due to $\mathrm{PV}$ current change $(\Delta I)$ while $\Delta V$ is almost zero. In order to reach the new MPP 'M', the MPPT algorithm must decrement the duty ratio $D$. Hence, the algorithm performance is affected by the variable step adopted to achieve this decrement.

- For the conventional $\Delta P / \Delta V$ dependent step, the almost zero $\Delta V$ will result in a large step-size that vastly decrements $D$ and shifts the operation to point ' $\mathbf{C}$ '. Hence, a noticeable transient power loss occurs and the algorithm takes long time to reach the new MPP 'M'.

- For the proposed $\Delta P$ based step, the large step-size is avoided and $D$ is decremented to shift the operating point to ' $\mathbf{D}$ ' which is close to the MPP 'M'. This will fasten the tracking process and reduce transient power loss. 


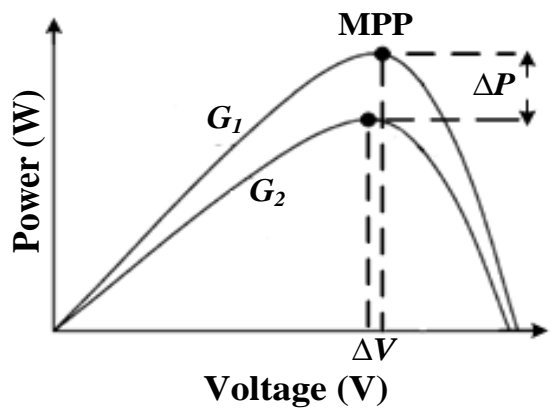

(a)

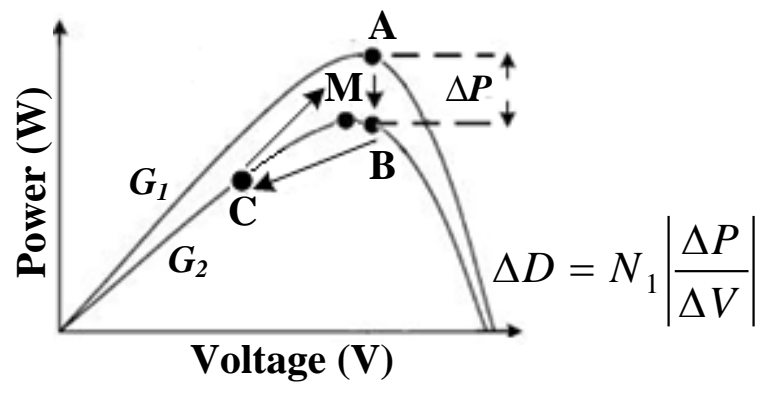

(b)

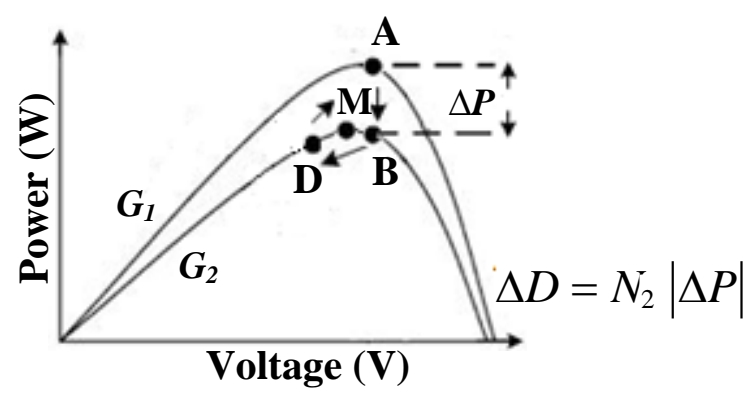

(c)

Fig. 3: Effect of irradiance change on MPP (a) peak PV power shift, MPPT performance adopting: (b) conventional $\Delta P / \Delta V$ based variable step, and (c) proposed $\Delta P$ based variable step

\section{Simulation work}

Simulation work has been carried out to compare the steady-state and transient performance of the conventional Inc.Cond. technique applying the conventional $\Delta P / \Delta V$ dependent variable step-size with that of the proposed division-free Inc.Cond. method adopting the proposed $\Delta P$ based variable step-size. This is performed under two step changes in irradiance levels (from $1000 \mathrm{~W} / \mathrm{m}^{2}$ to $400 \mathrm{~W} / \mathrm{m}^{2}$ at $0.2 \mathrm{~s}$ then from $400 \mathrm{~W} / \mathrm{m}^{2}$ to $700 \mathrm{~W} / \mathrm{m}^{2}$ at $0.4 \mathrm{~s}$.), at $25^{\circ} \mathrm{C}$. A KD135SX_UPU PV module is utilized with specifications given in appendix. Moreover, the applied DC-DC boost converter parameters are given as follows:

Chopper inductance $(L): 2.3 \mathrm{mH}, \quad$ Switching frequency $\left(f_{s w}\right): 15 \mathrm{kHz} \quad$ and $\quad V_{\text {battery }}=3 \times 12 \mathrm{~V}$

TABLE I. SIMULATION PERFORMANCE INDICATORS OF THE CONVENTIONAL AND PROPOSED TECHNIQUES UNDER TWO STEP CHANGES IN IRRADIANCE

\begin{tabular}{|c|c|c|c|c|c|}
\hline \multirow{2}{*}{ Condition } & $\begin{array}{c}\text { Variable-step } \\
\text { MPPT method }\end{array}$ & \multicolumn{2}{|c|}{ Transient } & \multicolumn{2}{c|}{ Steady-state } \\
\cline { 3 - 6 } & $\begin{array}{c}\text { Undershoot } \\
\left(\% P_{P V}\right)\end{array}$ & $\begin{array}{c}\text { Settling } \\
\text { time }(\mathbf{s})\end{array}$ & $\begin{array}{c}\text { Sscillations } \\
\text { at MPP }(W)\end{array}$ & $\begin{array}{c}\text { MPPT } \\
\text { efficiency } \\
(\% \zeta)\end{array}$ \\
\hline \multirow{2}{*}{ Start-up } & Conv. $(\Delta P / \Delta V)$ & $84.96 \%$ & 0.024 & 4.25 & $98.7 \%$ \\
\cline { 2 - 6 } & Proposed $(\Delta P)$ & $60.15 \%$ & 0.04 & 0.0125 & $98.7 \%$ \\
\hline $\begin{array}{c}\text { From } \\
1000 \mathrm{~W} / \mathrm{m}^{2} \text { to } \\
400 \mathrm{~W} / \mathrm{m}^{2}\end{array}$ & Conv. $(\Delta P / \Delta V)$ & $66.63 \%$ & 0.021 & 1.5 & $98.6 \%$ \\
\cline { 2 - 6 } & Proposed $(\Delta P)$ & $43.67 \%$ & 0.014 & 0.0025 & $99.94 \%$ \\
\hline $\begin{array}{c}\text { From } \\
400 \mathrm{~W} / \mathrm{m}^{2} \\
\text { to } 700 \mathrm{~W} / \mathrm{m}^{2}\end{array}$ & Conv. $(\Delta P / \Delta V)$ & $89.35 \%$ & 0.022 & 3.5 & $98.3 \%$ \\
\cline { 2 - 6 } & Proposed $(\Delta P)$ & $28.5 \%$ & 0.01 & 0.022 & $98.4 \%$ \\
\hline
\end{tabular}




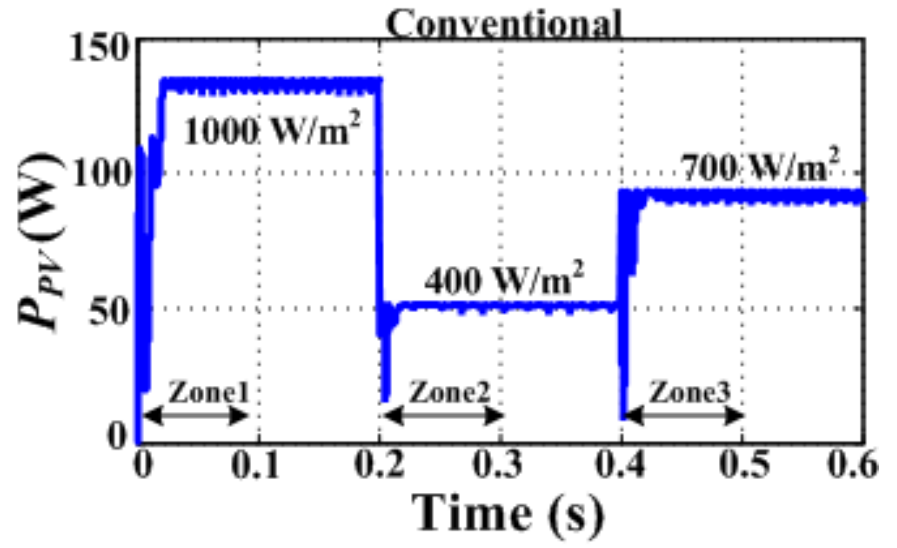

(a)

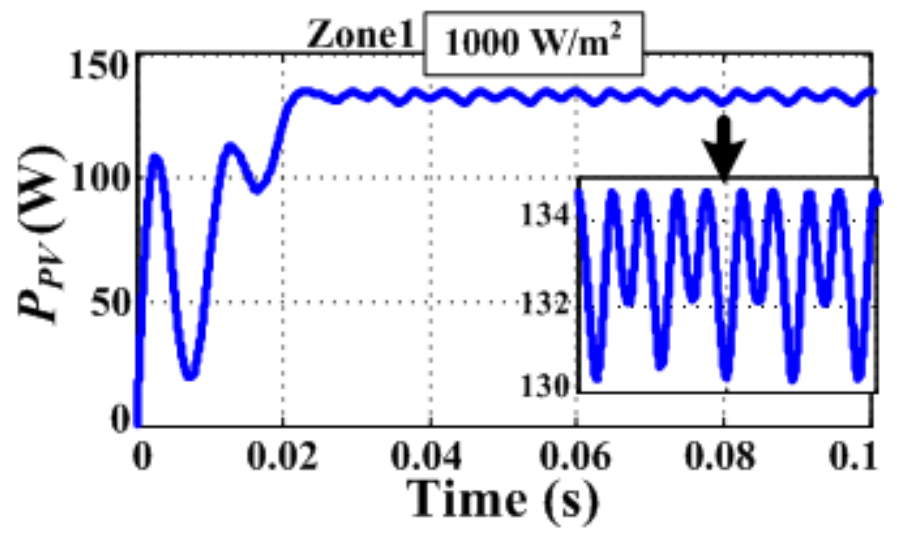

(b)

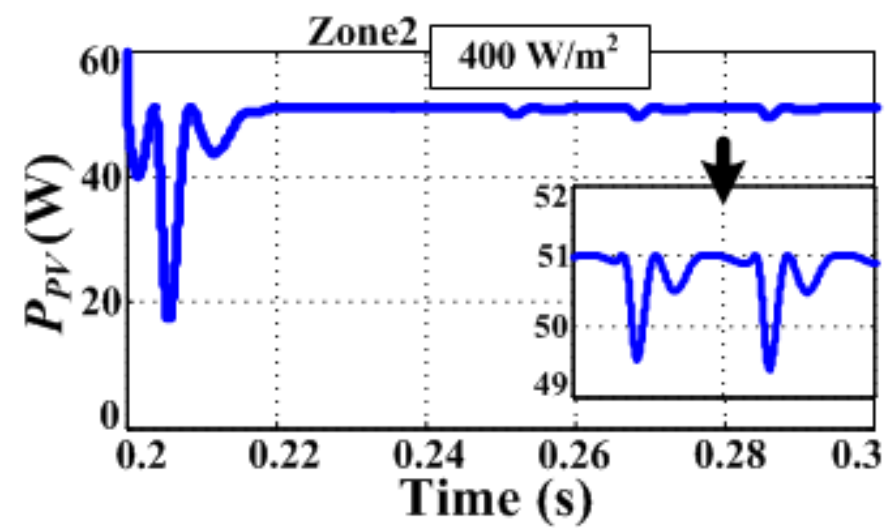

(c)

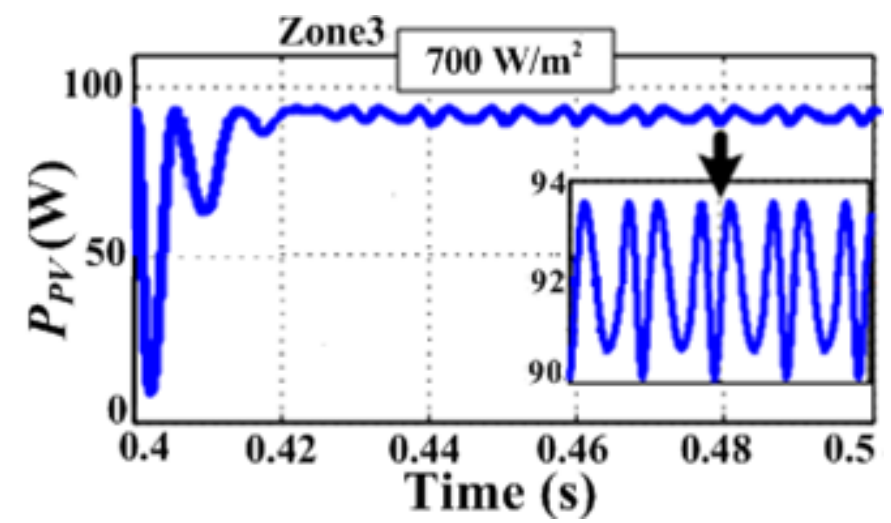

(d)

Fig. 4: Simulation results of the conventional Inc.Cond. method adopting the conventional $\Delta P / \Delta V$ based variable step under varying irradiance (a) Overall PV power with zoom at (b) Start-up (c) First step change, (d) Second step change

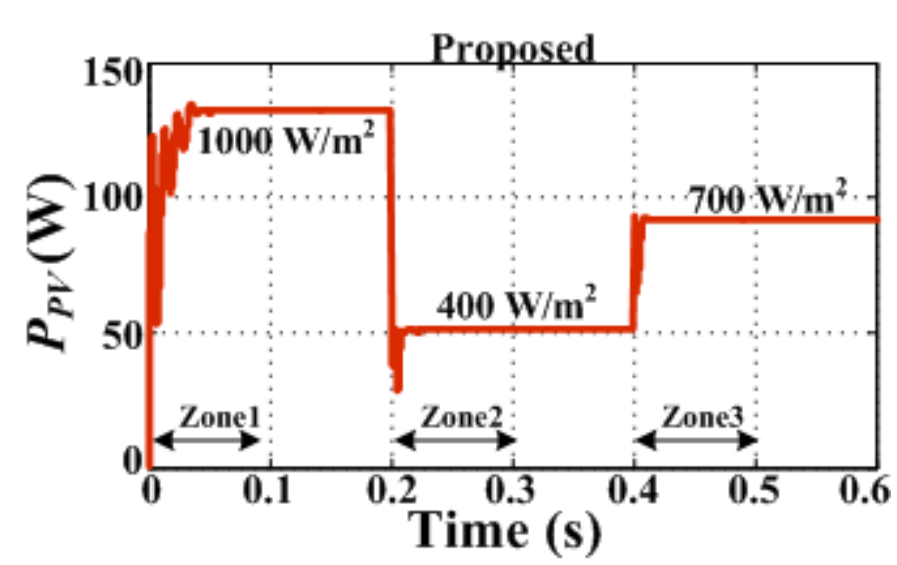

(a)

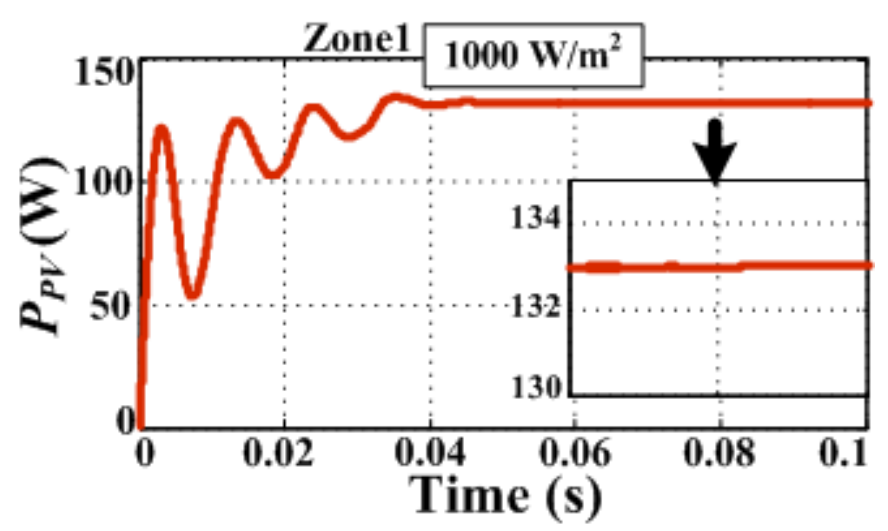

(b)

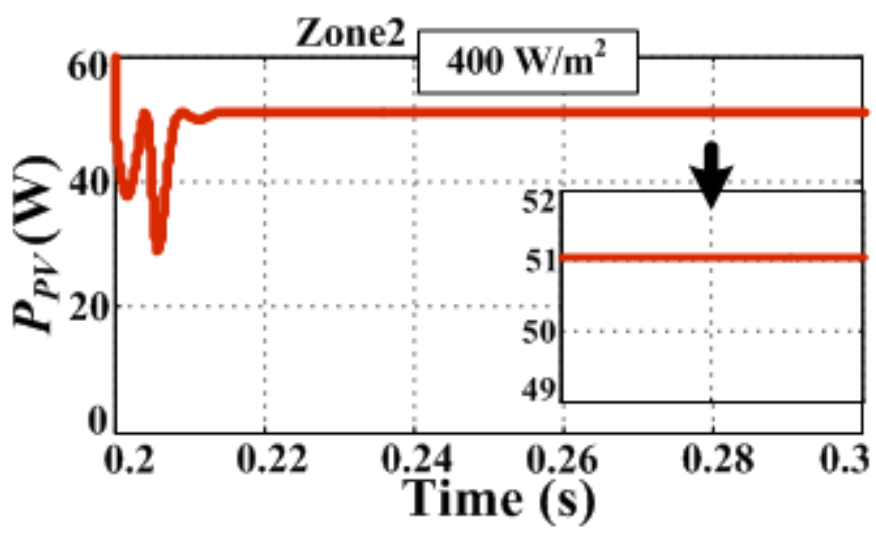

(c)

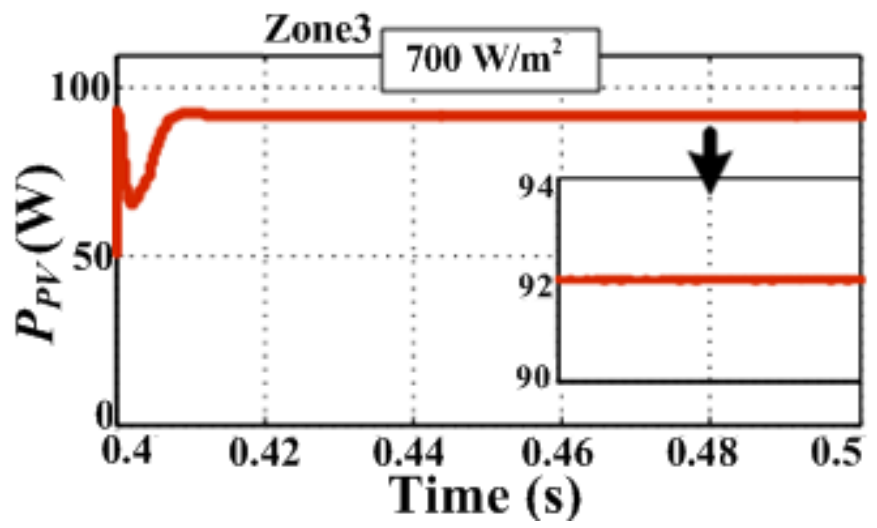

(d)

Fig. 5: Simulation results of the modified Inc.Cond. method adopting the proposed $\Delta P$ based variable step under varying irradiance (a) Overall PV power with zoom at (b) Start-up (c) First step change, (d) Second step change 
Figures 4 and 5 show the performance of the conventional technique and that of the proposed one respectively during the considered step changes in irradiance while Table I gives their steady-state and transient performance parameters. It can be concluded that; under varying irradiance conditions, both techniques can successfully track the PV maximum power yet with different levels of tracking accuracy, speed and transient undershoot.

Figure 4 parts (a-d) show transient and steady state performance of the conventional method at start-up, first and second irradiance step changes respectively. The latter is repeated for the proposed technique as shown in fig. 5 parts (a-d). It's observable, that the elimination of the division by $\Delta V$ in the proposed step-size has limited the large increase in the step thus minimizing the steady-state oscillations around the MPP on the penalty of slower tracking speed at the beginning of PV system operation. However, during sudden irradiance changes, the proposed variable step gives better transient performance and faster response.

Considering Table I, the MPP tracking time, acquired by the proposed technique, is reduced by $33.3 \%$ and by $54.55 \%$ of that achieved by the conventional technique at the first and the second step changes respectively. Furthermore, the proposed step succeeded in reducing the power undershoot by almost $24.8 \%, 23 \%$ and $60.85 \%$ of the maximum tracked PV power at $1000 \mathrm{~W} / \mathrm{m}^{2}$, $400 \mathrm{~W} / \mathrm{m}^{2}$ and $700 \mathrm{~W} / \mathrm{m}^{2}$ respectively. Finally, the minimal steady-state power oscillations, encountered by the proposed technique, enhance its MPPT efficiency when compared to that of the conventional technique. Tracking efficiency can be defined as the percentage ratio of the tracked PV power by the considered MPPT algorithm at certain environmental conditions to the peak PV power under same conditions.

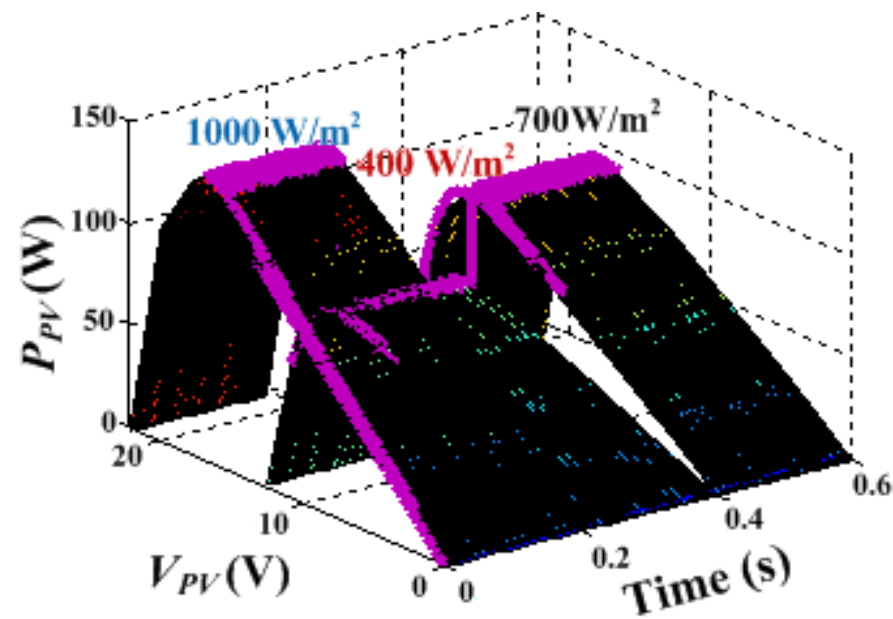

(a)

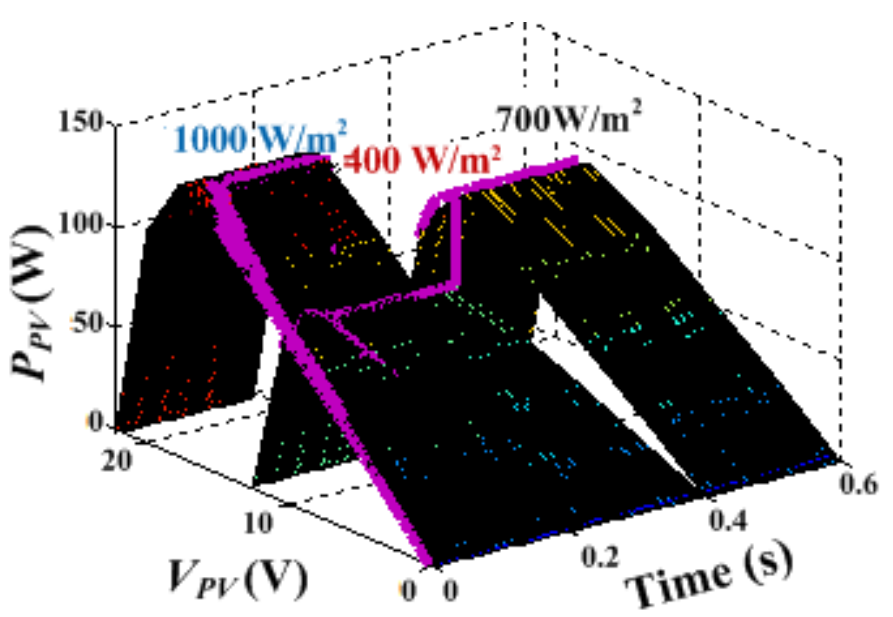

(b)

Fig. 6: Power tracking nature on module $P-V$ curves for (a) Conventional technique adopting $\Delta P / \Delta V$ step, (b) Proposed division-free technique with $\Delta P$ step.

The 3-D fig. 6 parts (a) and (b) illustrate PV power, tracked by the conventional and the proposed techniques respectively, versus PV voltage and time. These figures give more clarification on both techniques' tracking performance on the $P-V$ curves of the PV module during the considered step changes in irradiance. It's clear that the proposed technique exerts less steady-state power oscillations around the MPP of each $P-V$ curve relative to each irradiance level. Furthermore, it shows faster response during irradiance changes with less power undershoot. 
For further verification of the superiority of the proposed technique under changes, both techniques are retested at fixed irradiance of $1000 \mathrm{~W} / \mathrm{m}^{2}$ under two step changes in temperature (from $25^{\circ} \mathrm{C}$ to $40^{\circ} \mathrm{C}$ at $0.2 \mathrm{~s}$ then from $40{ }^{\circ} \mathrm{C}$ to $15^{\circ} \mathrm{C}$ at $0.4 \mathrm{~s}$.)

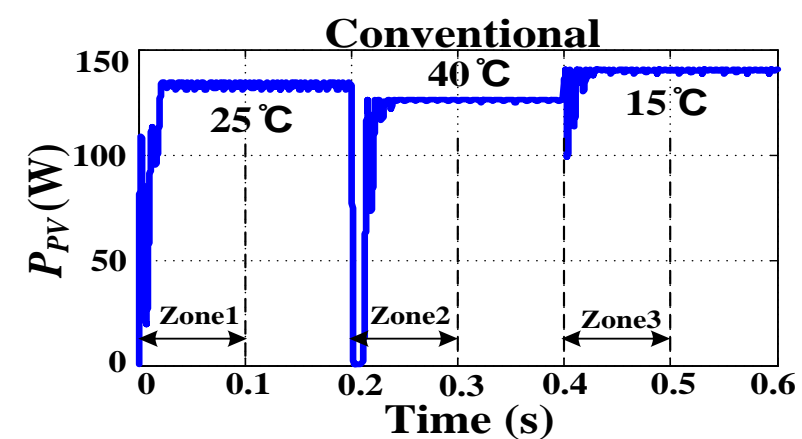

(a)

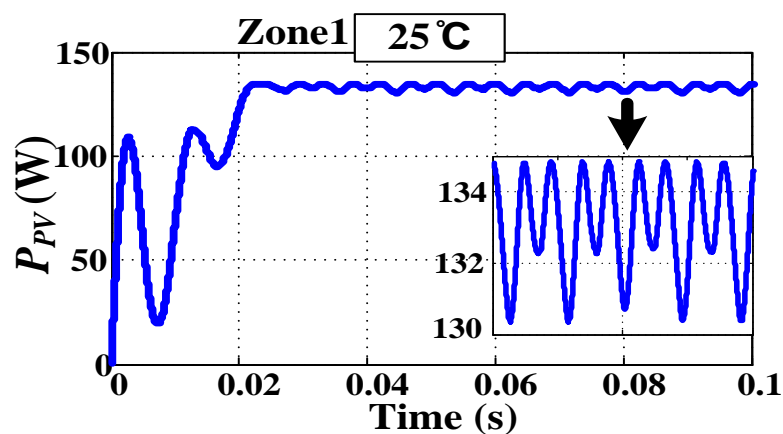

(b)

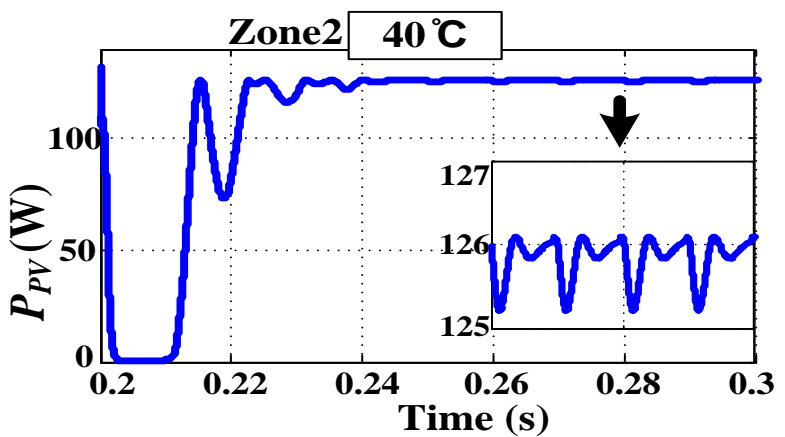

(c)

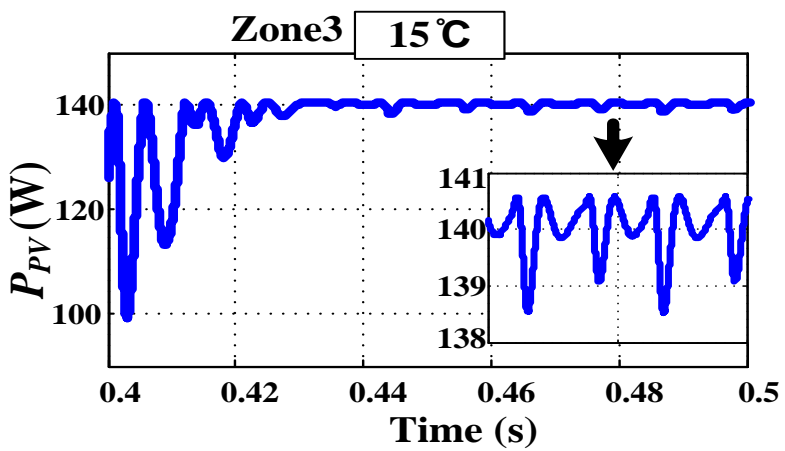

(d)

Fig.7: Simulation results of the conventional Inc.Cond. method adopting $\Delta P / \Delta V$ based variable step under varying temperature (a) Overall PV power with zoom at (b) Start-up (c) First step change, (d) Second step change

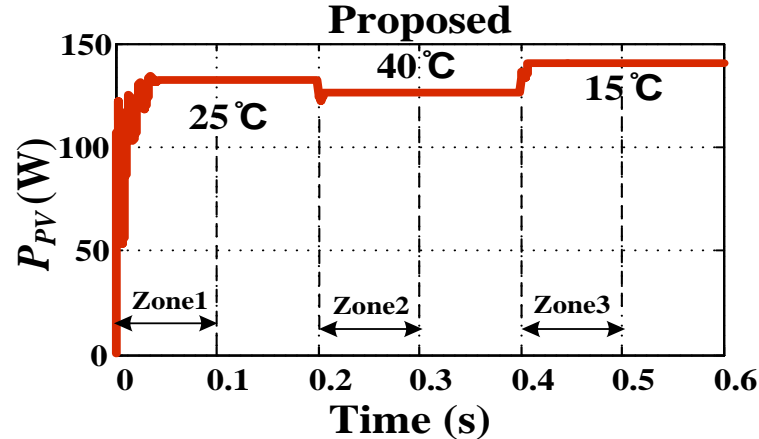

(a)

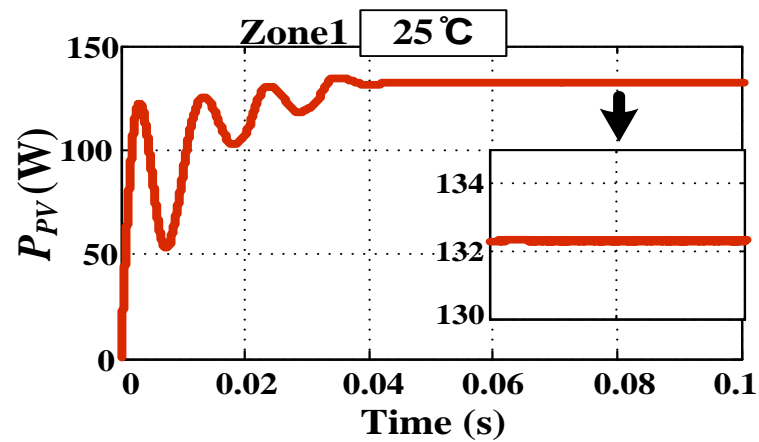

(b)

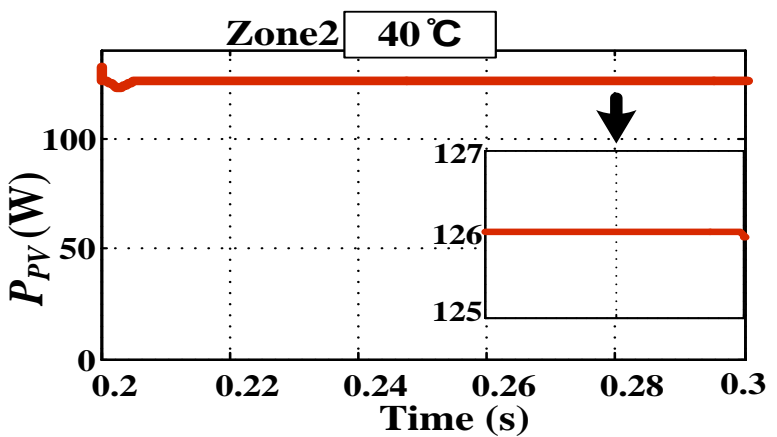

(c)

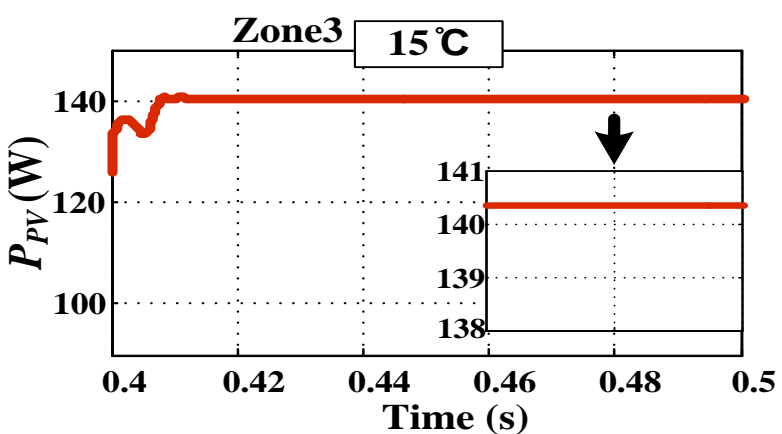

(d)

Fig. 8: Simulation results of the proposed 1 Inc.Cond. method adopting $\Delta P$ based variable step under varying temperature (a) Overall PV power with zoom at (b) Start-up (c) First step change,

(d) Second step change 
TABLE II. SIMULATION PERFORMANCE INDICATORS OF THE CONVENTIONAL AND PROPOSED TECHNIQUES UNDER TWO STEP CHANGES IN TEMPERATURE

\begin{tabular}{|c|c|c|c|c|c|}
\hline \multirow{2}{*}{ Condition } & \multirow{2}{*}{$\begin{array}{c}\text { Variable-step } \\
\text { MPPT method }\end{array}$} & \multicolumn{2}{|c|}{ Transient } & \multicolumn{2}{c|}{ Steady-state } \\
\cline { 3 - 6 } & & $\begin{array}{c}\text { Undershoot } \\
(\% \text { PPV })\end{array}$ & $\begin{array}{c}\text { Settling } \\
\text { time }(s)\end{array}$ & $\begin{array}{c}\text { Oscillations } \\
\text { at MPP }(W)\end{array}$ & $\begin{array}{c}\text { MPPT } \\
\text { efficiency } \\
(\%)\end{array}$ \\
\hline \multirow{2}{*}{ Start-up } & Conv. $(\Delta P / \Delta V)$ & $85.4 \%$ & 0.025 & 4.4 & $98.7 \%$ \\
\cline { 2 - 6 } & Proposed $(\Delta P)$ & $60 \%$ & 0.045 & 0.013 & $98.7 \%$ \\
\hline \multirow{2}{*}{$\begin{array}{c}\text { From } \\
25^{\circ} \mathrm{C} \text { to } 40^{\circ} \mathrm{C}\end{array}$} & Conv. $(\Delta P / \Delta V)$ & $100 \%$ & 0.04 & 1 & $99.68 \%$ \\
\cline { 2 - 6 } & Proposed $(\Delta P)$ & $2.94 \%$ & 0.0075 & 0.003 & $99.94 \%$ \\
\hline \multirow{2}{*}{$\begin{array}{c}\text { From } \\
40^{\circ} \mathrm{C} \text { to } 15^{\circ} \mathrm{C}\end{array}$} & Conv. $(\Delta P / \Delta V)$ & $28.74 \%$ & 0.03 & 2 & $99.45 \%$ \\
\cline { 2 - 6 } & Proposed $(\Delta P)$ & $4.87 \%$ & 0.019 & 0.005 & $99.83 \%$ \\
\hline
\end{tabular}

Figures 7 and 8 show the performance of the conventional technique and that of the proposed one respectively during the considered step changes in temperature while Table II gives their steady-state and transient performance parameters. It can be concluded that; under varying temperature conditions, both techniques can successfully track the PV maximum power yet with different levels of tracking accuracy, speed and transient undershoot.

Figure 7 parts (a-d) show transient and steady state performance of the conventional method at start-up, first and second temperature step changes respectively. The latter is repeated for the proposed technique as shown in fig. 8 parts (a-d). It's observable, that the elimination of the division by $\Delta V$ in the proposed step-size has limited the large increase in the step thus minimizing the steady-state oscillations around the MPP on the penalty of slower tracking speed at the beginning of PV system operation. However, during sudden temperature changes, the proposed step gives better transient performance and faster response.

Considering Table II, the MPP tracking time, acquired by the proposed technique, is reduced by $81.25 \%$ and by $36.67 \%$ of that achieved by the conventional technique at the first and the second step changes respectively. Furthermore, the proposed step succeeded in reducing the power undershoot by almost $25.4 \%, 97 \%$ and $23.87 \%$ of the maximum tracked $\mathrm{PV}$ power at $25^{\circ} \mathrm{C}, 40^{\circ} \mathrm{C}$ and $15^{\circ} \mathrm{C}$ respectively. Finally, the minimal steady-state power oscillations, encountered by the proposed technique, enhance its MPPT efficiency when compared to that of the conventional technique.

Hence, simulation results show that the proposed technique's steady-state and transient performances outweigh those of the conventional one, owing to its applied $\Delta P$-based variable step-size, yet with simpler implementation due the entire division calculations elimination from its algorithm structure. This is done under sudden irradiance changes as well as under sudden temperature changes which in turn verifies the effectiveness and superiority of the proposed variable-step Inc.Cond. technique under different environmental changes. 


\section{Experimental work}

The merit of division elimination, from the Inc.Cond. algorithm, mainly lies in simplifying its structure and enhancing its performance when being implemented by low cost microcontrollers. To clarify the latter, an experimental rig employing ARDUINO Uno board, based on low cost Atmega328 16-bit microcontroller, is set and tested.

The conventional Inc.Cond. technique, featuring several division computations and applying the $\Delta P / \Delta V$ step-size, as well as the proposed division-free IncCond. method, adopting the $\Delta P$ step-size, are both implemented using ARDUINO Uno board. The execution time for both schemes has to be measured in order to choose the most convenient sampling time. Hence, it is calculated by programming a pilot pin to toggle during program execution and triggers a digital output. Figure 9(a) shows the program execution time for the conventional technique which is $400 \mu$ s while fig. 9(b) shows that of the proposed technique which is $300 \mu$ s. It's clear that the elimination of the many division calculations in the proposed algorithm decreases the execution time and consequently simplifies the controller operation. However, for fair comparison, same sampling time is chosen for both techniques which is 450 $\mu$ s (to exceed the larger execution time of the conventional algorithm).

A real-time comparison between the proposed Inc.Cond. technique and the conventional one is carried out to verify the superiority of the former. This is carried out during fixed and changing environmental conditions as illustrated in the following subsections.

\section{A. Stable environmental conditions}

First, the performance of both the conventional and proposed variable-step Inc.Cond. techniques, are tested under fixed environmental conditions $\left(800 \mathrm{~W} / \mathrm{m}^{2}\right.$ and $\left.23^{\circ} \mathrm{C}\right)$. A KD135SX_UPU PV panel is employed. Figure 9 (c) shows the performance of the conventional technique employing $\Delta P / \Delta V$-based variable step-size while fig. 9 (d) shows that of the proposed division-free technique applying $\Delta P$-based step. The proposed step-size minimizes the steady-state oscillation around the MPP, thus maximizing tracking accuracy. 


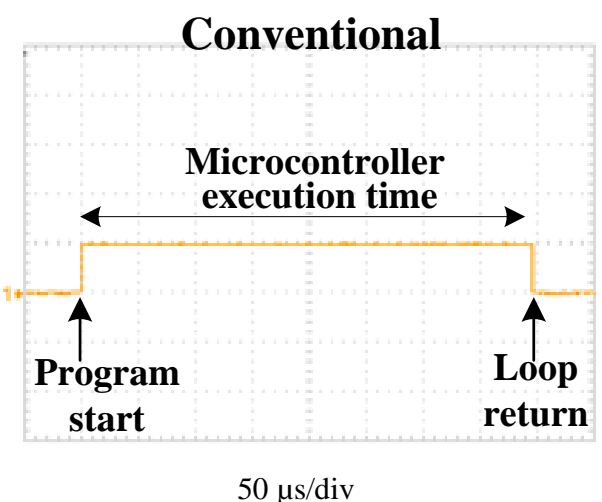

(a)

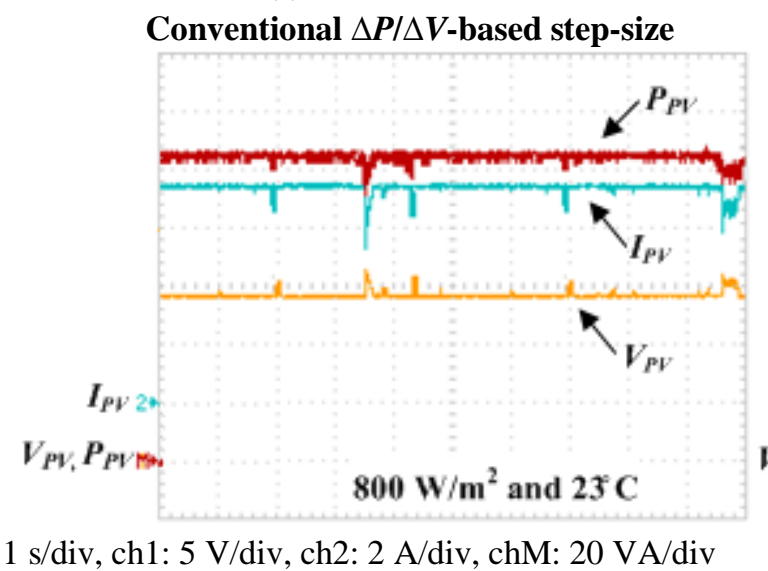

(c)

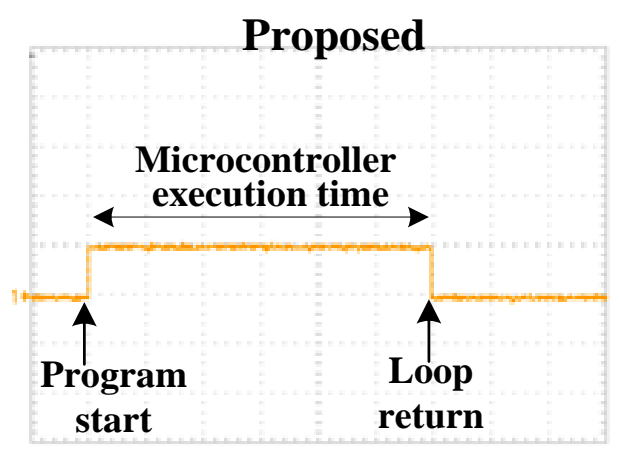

$50 \mu \mathrm{s} / \mathrm{div}$

(b)

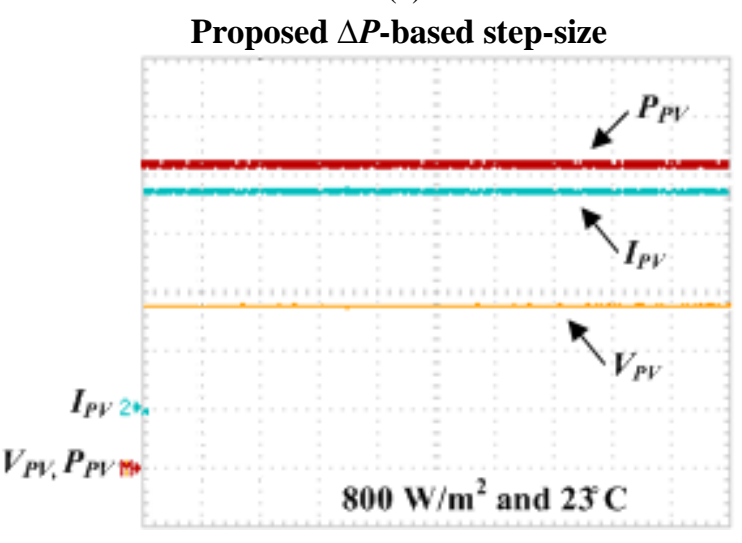

$1 \mathrm{~s} / \mathrm{div}, \mathrm{ch} 1: 5 \mathrm{~V} / \mathrm{div}, \mathrm{ch} 2: 2 \mathrm{~A} / \mathrm{div}, \mathrm{chM}: 20 \mathrm{VA} / \mathrm{div}$

(d)

Figure 9: Experimental results (a) conventional technique execution time adopting $\Delta P / \Delta V$ step, (b) proposed technique execution time adopting $\Delta P$ step, (c) conventional technique performance adopting $\Delta P / \Delta V$ step and (d) proposed division-free technique performance with $\Delta P$ step, using KD135X-UPU panel under steady-state conditions $\left(800 \mathrm{~W} / \mathrm{m}^{2}\right.$ and $\left.23^{\circ} \mathrm{C}\right)$.

\section{B. Sudden changing irradiance conditions}

In order to compare the transient performance of both techniques under sudden changes, a step change should be created.

This is not practical with roof-mounted PV panels as their surrounding environmental conditions are uncontrollable. Thus, the need of PV module simulator to replace actual PV panel is mandatory. However, these simulators are expensive instruments and not always affordable. Thus, a lower-cost way of simulating $I-V$ and $P-V$ curves similar in nature to those generated by a PV panel is applied in [33]. This paper presents a simplified circuit which employs a variable resistance $\left(R_{s}\right)$ in series with a variable voltage DC power supply and the MPPT tracker (boost converter) is connected at its output. This circuit produces a $P$ - $V$ curve that exhibits a peak point for the tracker to lock on. Changing the variable series resistance will result in another $P$ - $V$ change with a new MPP to track.

Similarly, a simplified PV simulating circuit is employed, in this paper, as shown in fig. 10(a). This circuit simulates the PV source when exposed to sudden step change in irradiance. It consists of a DC power supply with constant voltage of $28 \mathrm{~V}$ and two parallel resistances of $3.2 \Omega$ each in order to represent $R_{s}$. When the switch $\mathrm{S}$ is on, the two resistances are in parallel and $R_{s}$ is $1.6 \Omega$ and this gives a $P$ - $V$ curve of almost $120 \mathrm{~W}$ peak power. When $\mathrm{S}$ is opened, $R_{s}$ becomes $3.2 \Omega$ and a step decrease in the current $I$ occurs which results in a step decrease in the power level to about $60 \mathrm{~W}$ as shown in fig. 10(b). 
Figure 11 parts (a) and (b) show the performances of the conventional and the proposed Inc.Cond. techniques respectively, under a step decrease in the PV simulator power level (from $120 \mathrm{~W}$ to $60 \mathrm{~W}$ ). It's clear that the $\Delta P / \Delta V$ step applied in the conventional scheme exhibits more steady-state power oscillations around the MPP than those acquired by the proposed $\Delta P$ step-size employed in the modified scheme. Meanwhile, when zooming around both schemes' transient response during the step-change, as shown in fig. 11 parts (c) and (d), the conventional step-size shows slower response with settling time $\left(t_{s}\right)$ equals to $400 \mathrm{~ms}$ which is four times that of the settling time experienced by the proposed step $\left(t_{s}=100 \mathrm{~ms}\right)$.

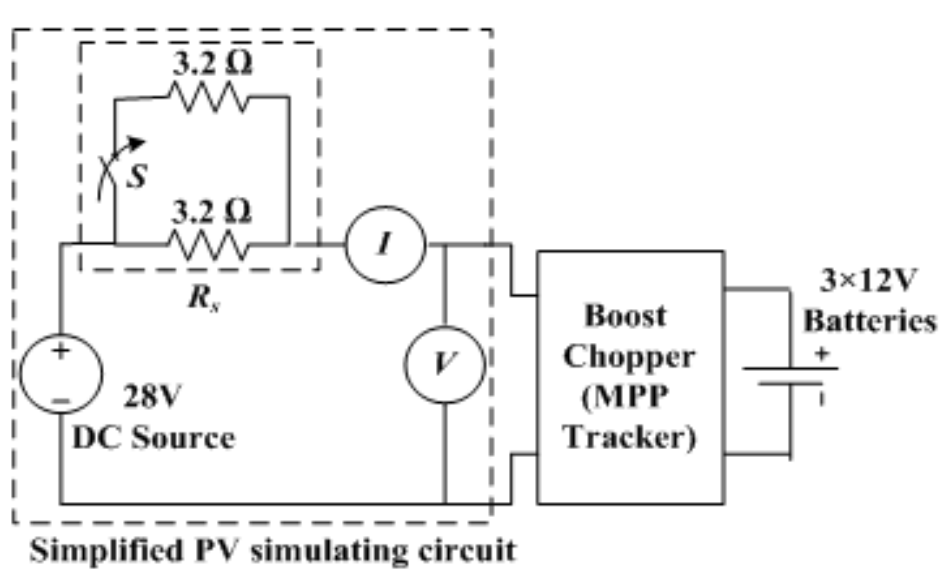

(a)

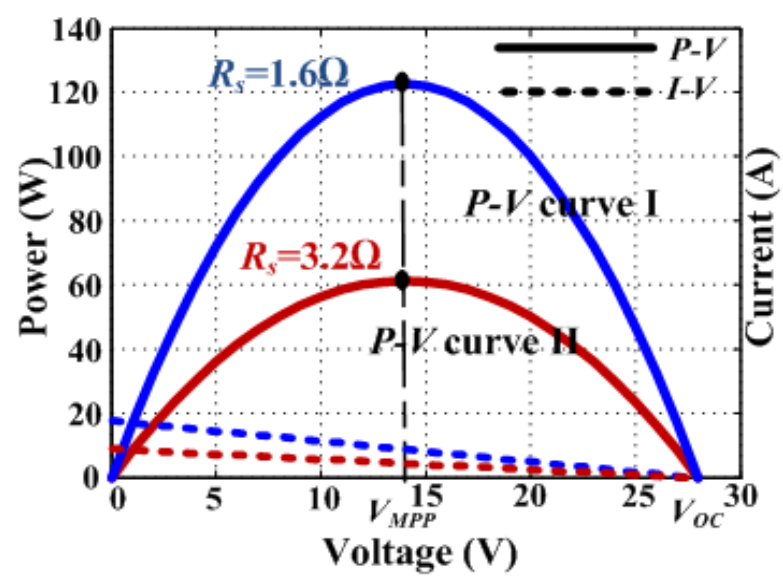

(b)

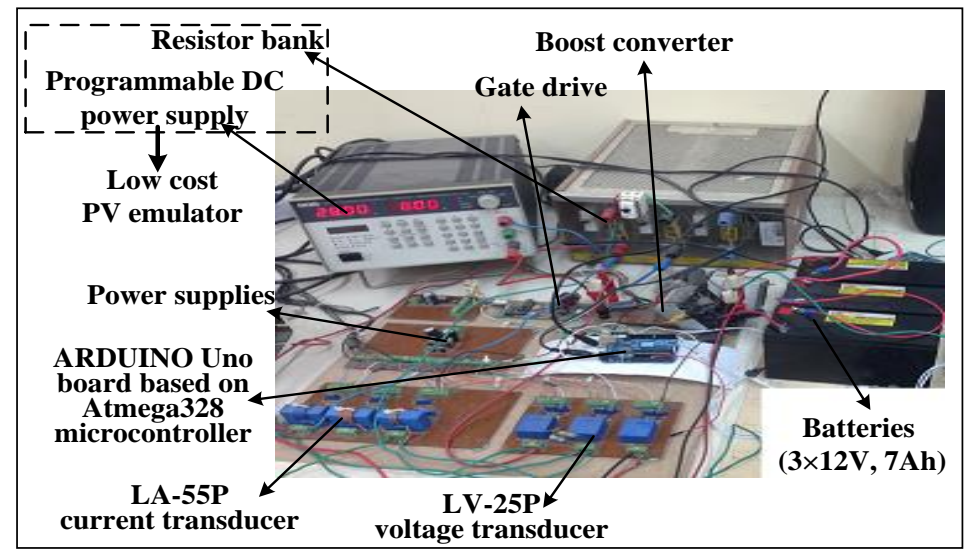

(c)

Fig. 10: Experimental setup (a) Low cost PV emulator schematic diagram, (b) $P-V, I-V$ characteristic curves of PV simulating circuit for two different values of $R_{s}$, and (c) test-rig photography 


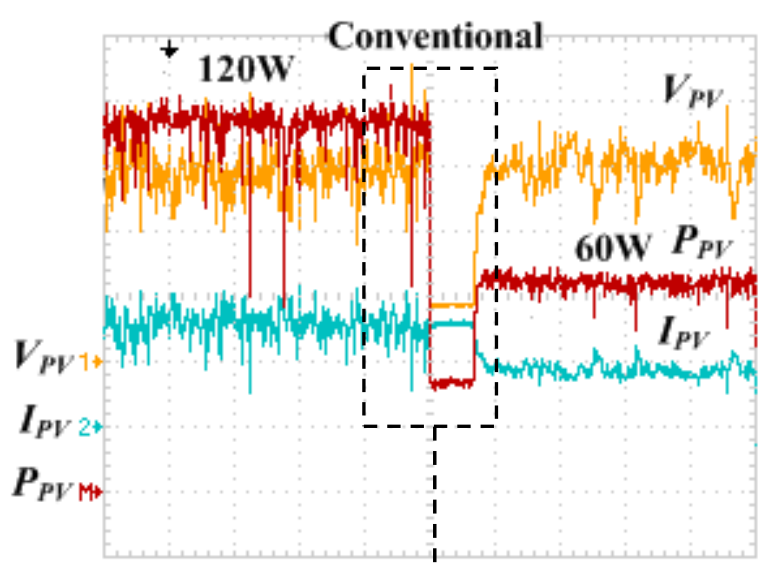

(a) $500 \mathrm{~ms} / \mathrm{div}$, ch1: $5 \mathrm{~V} / \mathrm{div}$, ch2: $5 \mathrm{~A} / \mathrm{div}$, chM: $20 \mathrm{VA} / \mathrm{div}$

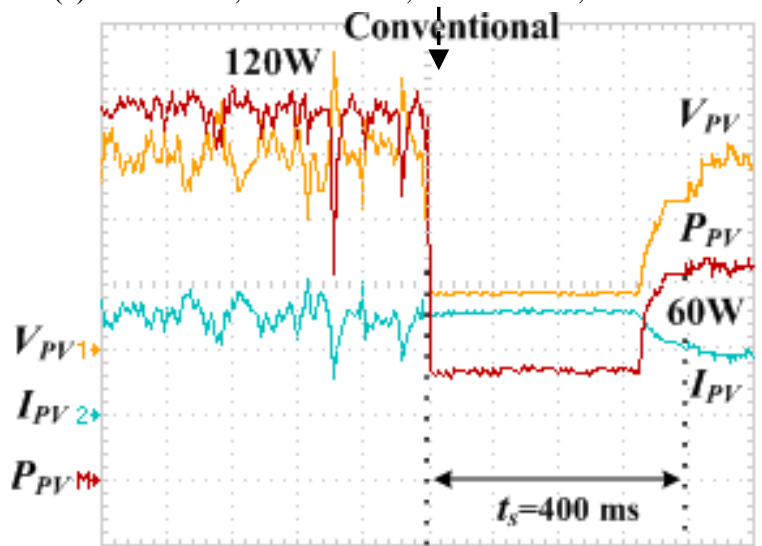

(c)100 ms/div, ch1: $5 \mathrm{~V} / \mathrm{div}, \mathrm{ch} 2: 5 \mathrm{~A} / \mathrm{div}$, chM: $20 \mathrm{VA} / \mathrm{div}$

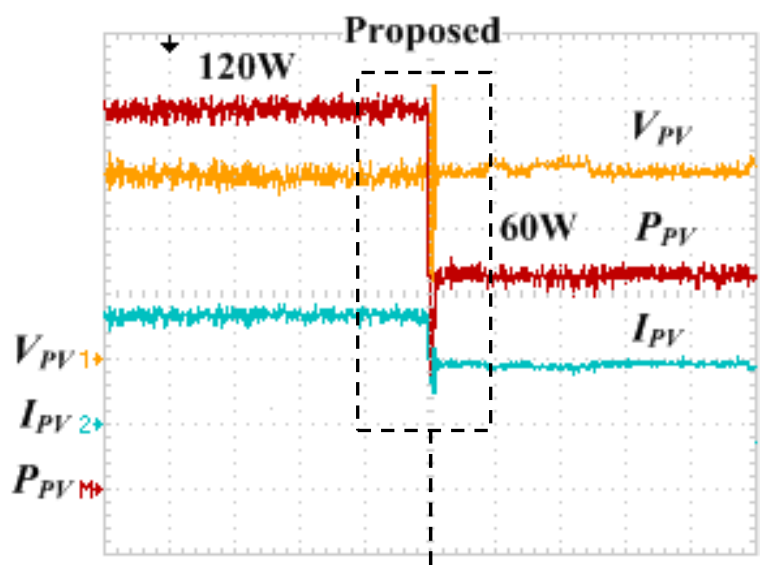

(b) $500 \mathrm{~ms} / \mathrm{div}$, ch1: $5 \mathrm{~V} / \mathrm{div}$, ch2: $5 \mathrm{~A} / \mathrm{div}$, chM: $20 \mathrm{VA} / \mathrm{div}$

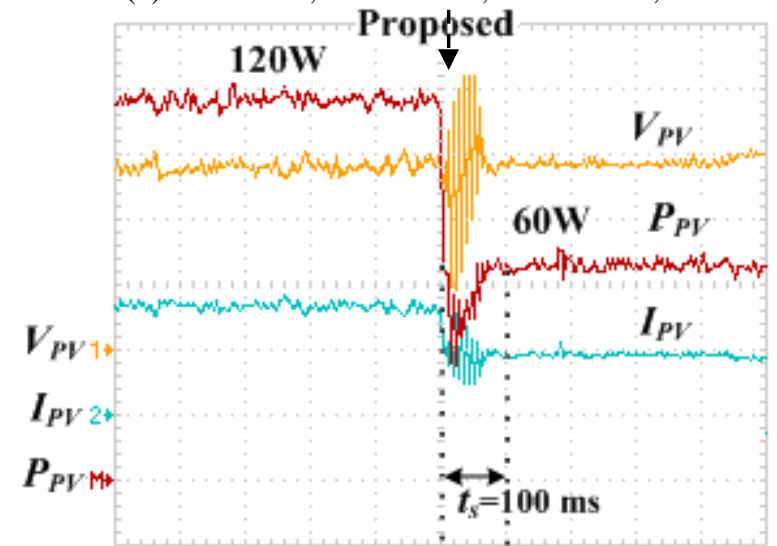

(d)100 ms/div, ch1: 5 V/div, ch2: 5 A/div, chM: $20 \mathrm{VA} /$ div.

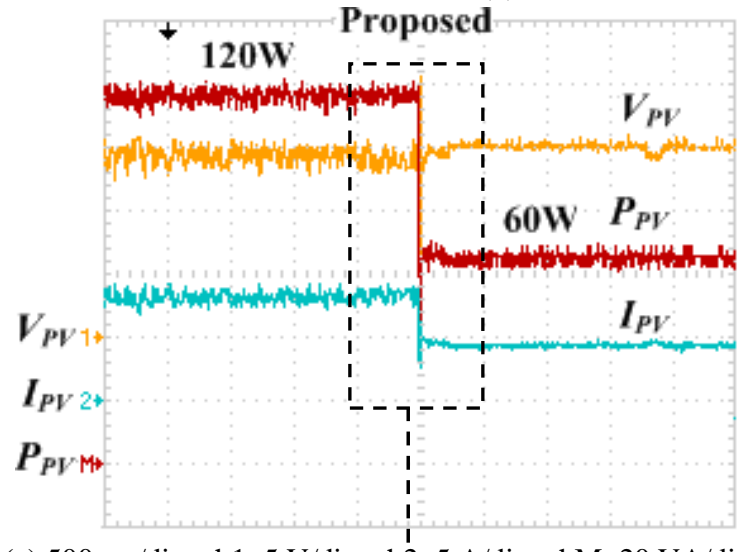

(e) $500 \mathrm{~ms} / \mathrm{div}$, ch1: $5 \mathrm{~V} / \mathrm{div}$, chR: $5 \mathrm{~A} / \mathrm{div}$, chM: $20 \mathrm{VA} / \mathrm{div}$

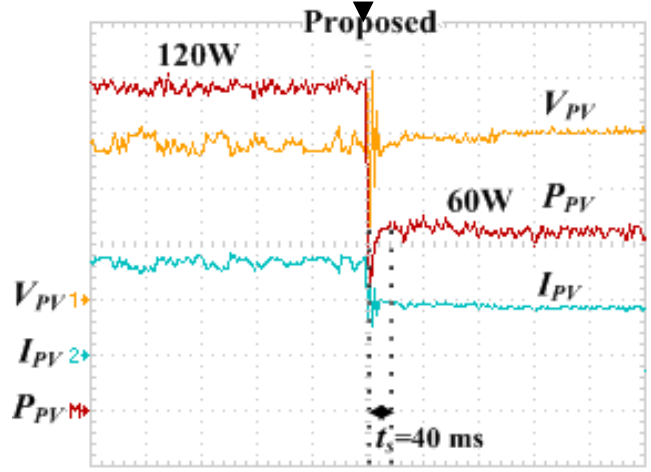

(f) $100 \mathrm{~ms} / \mathrm{div}$, ch1: $5 \mathrm{~V} / \mathrm{div}$, ch2: $5 \mathrm{~A} / \mathrm{div}$, chM: $20 \mathrm{VA} / \mathrm{div}$.

Fig. 11: Step change experimental results, using a PV emulator, at $T_{\text {sampling }}=450 \mu$ s for (a) conventional technique adopting $\Delta P / \Delta V$ step, (b) proposed division-free technique adopting $\Delta P$ step, (c) Zoom of fig. 11(a), (d) Zoom of fig. 11(b), Step change experimental results, using a PV emulator, at $T_{\text {sampling }}=350 \mu$ s for (e) Proposed division-free technique adopting $\Delta P$ step and (f) Zoom of fig. 11(e) 
Thus, at the same sampling time, the proposed technique shows better performance due to its employed $\Delta P$-based step-size. However, since this division-free technique exhibits less processing time $(300 \mu \mathrm{s})$, its performance can be retested at a sampling time of $350 \mu \mathrm{s}$ which is less than that adopted in the previous case. This improves the sampling rate which fastens system response during changes. Fig. 11(e) shows the proposed algorithm performance during the step decrease in power level at a sampling time of $350 \mu$ s. A zoom around this step-change is given by fig. 11(f). The settling time $\left(t_{s}\right)$ of the proposed scheme, in this case, is $40 \mathrm{~ms}$ which is less than half that exhibited by the same scheme applying $450 \mu$ sec sampling time shown in fig.11(d).

In conclusion, experimental results verify that the proposed step-size enhances system steady-state and transient performance during changes. Meanwhile the division computations elimination reduces the program execution time enabling the user to improve the sampling rate which introduces further enhancement to the technique response during transients. The test rig for the considered system in this section is shown in fig. 10(c). 
Table III: Comparison between the proposed technique, implemented by Atmega 328 microcontroller, and experimental prototypes presented in recent publications

\begin{tabular}{|c|c|c|c|c|c|c|c|c|c|}
\hline \begin{tabular}{|c|} 
Work, \\
Publication \\
year
\end{tabular} & $\begin{array}{l}\text { Power } \\
\text { rating }\end{array}$ & $\begin{array}{c}\text { Converter } \\
\text { type }\end{array}$ & $\begin{array}{l}\text { Switching } \\
\text { frequency }\end{array}$ & \begin{tabular}{|c|} 
MPPT \\
Technique
\end{tabular} & $\begin{array}{c}\text { Hardware } \\
\text { Programmed } \\
\text { platform }\end{array}$ & \begin{tabular}{|c|} 
Accuracy- \\
Power \\
oscillations
\end{tabular} & $\begin{array}{l}\text { Tracking } \\
\text { efficiency }\end{array}$ & $\begin{array}{c}\text { Tracking } \\
\text { speed }\end{array}$ & $\begin{array}{c}\text { Price of } \\
\text { programmer }\end{array}$ \\
\hline $\begin{array}{|ll|}{[27]} & (2014) \\
\end{array}$ & $80 \mathrm{~W}$ & Buck & $100 \mathrm{kHz}$ & Inc.Cond. & FPGA XC3S400 & $\begin{array}{l}2.7 \mathrm{~W} \\
(3.4 \%)\end{array}$ & $98.8 \%$ & $2.5 \mathrm{~ms}$ & $\$ 38.5$ \\
\hline [9] (2013) & $200 \mathrm{~W}$ & Boost & $50 \mathrm{kHz}$ & $\begin{array}{c}\text { P\&O-based } \\
\text { on PI } \\
\text { controller }\end{array}$ & $\begin{array}{c}\text { DSP } \\
\text { TMS320F240 }\end{array}$ & $\begin{array}{l}20 \mathrm{~W} \\
(10 \%)\end{array}$ & $95 \%$ & $20 \mathrm{~ms}$ & $\$ 25.64$ \\
\hline \begin{tabular}{|l|} 
[34] (2012) \\
\end{tabular} & $240 \mathrm{~W}$ & $\begin{array}{l}\text { Buck- } \\
\text { boost }\end{array}$ & $50 \mathrm{kHz}$ & $\begin{array}{l}\text { Improved } \\
\text { PSO }\end{array}$ & $\begin{array}{c}\text { DSP } \\
\text { TMS320F240 }\end{array}$ & $\begin{array}{c}8 \mathrm{~W} \\
(3.33 \%)\end{array}$ & $96.5 \%$ & $40 \mathrm{~ms}$ & $\$ 25.64$ \\
\hline$[35](2014)$ & $800 \mathrm{~W}$ & Boost & ------------ & \begin{tabular}{|c|} 
Zero- \\
oscillation \\
adaptive \\
step P\&O
\end{tabular} & $\begin{array}{l}\text { Microcontroller } \\
\text { TI C2000 }\end{array}$ & $\begin{array}{c}20 \mathrm{~W} \\
(2.5 \%)\end{array}$ & $98.75 \%$ & $1 \mathrm{~s}$ & $\$ 24$ \\
\hline [14] (2012) & $\begin{array}{c}1080 \\
W\end{array}$ & Buck & $10 \mathrm{kHz}$ & $\mathrm{P} \& \mathrm{O}$ & $\begin{array}{c}\text { DSP } \\
\text { TMS320F2812 }\end{array}$ & $\begin{array}{c}20 \mathrm{~W} \\
(1.85 \%)\end{array}$ & $97.9 \%$ & $0.5 \mathrm{~s}$ & $\$ 23.32$ \\
\hline \begin{tabular}{|l|}
{$[26](2013)$} \\
\end{tabular} & $\begin{array}{c}1080 \\
W\end{array}$ & Buck & $10 \mathrm{kHz}$ & Inc.Cond. & $\begin{array}{c}\text { DSP } \\
\text { TMS320F2812 }\end{array}$ & $\begin{array}{c}20 \mathrm{~W} \\
(1.85 \%)\end{array}$ & $96.8 \%$ & $0.5 \mathrm{~s}$ & $\$ 23.32$ \\
\hline [36] (2011) & $10 \mathrm{~W}$ & Buck & $100 \mathrm{kHz}$ & $\begin{array}{c}\text { Load- } \\
\text { current } \\
\text { based } \\
\text { MPPT }\end{array}$ & $\begin{array}{c}\text { DSP } \\
\text { TMS320F28335 }\end{array}$ & $\begin{array}{l}0.04 \mathrm{~W} \\
(0.4 \%)\end{array}$ & $97 \%$ & $80 \mathrm{~ms}$ & $\$ 21.17$ \\
\hline [37] (2011) & $54 \mathrm{~W}$ & Boost & $25 \mathrm{kHz}$ & PI-P\&O & $\begin{array}{c}\text { DSP } \\
\text { TMS320F28335 } \\
\end{array}$ & $\begin{array}{c}7 \mathrm{~W} \\
(13 \%)\end{array}$ & $93 \%$ & $1 \mathrm{~s}$ & $\$ 21.17$ \\
\hline $\mid[38](2012)$ & $150 \mathrm{~W}$ & Buck & ----------- & $\begin{array}{c}\text { Fuzzy - } \\
\text { based P\&O }\end{array}$ & $\begin{array}{c}\text { DSP } \\
\text { TMS320F28335 }\end{array}$ & $\begin{array}{c}2 \mathrm{~W} \\
(1.3 \%)\end{array}$ & $98.5 \%$ & $1.5 \mathrm{~s}$ & $\$ 21.17$ \\
\hline [39] (2014) & $210 \mathrm{~W}$ & Boost & |---------- & \begin{tabular}{|c|} 
Adaptive \\
P\&O-fuzzy \\
MPPT \\
\end{tabular} & $\begin{array}{c}\text { DSP } \\
\text { TMS320F28335 }\end{array}$ & $\begin{array}{c}1 \mathrm{~W} \\
(0.5 \%)\end{array}$ & $95.2 \%$ & $20 \mathrm{~ms}$ & $\$ 21.17$ \\
\hline$[25](2011)$ & $110 \mathrm{~W}$ & Boost & $50 \mathrm{kHz}$ & Inc.Cond. & $\begin{array}{c}\text { Microcontroller } \\
\text { C515C }\end{array}$ & $\begin{array}{c}15 \mathrm{~W} \\
(1.4 \%)\end{array}$ & $96.8 \%$ & $0.5 \mathrm{~s}$ & $\$ 19.6$ \\
\hline [21] (2014) & 40W & $\begin{array}{c}\mathrm{DC} / \mathrm{DC} \\
\text { converter }\end{array}$ & $10 \mathrm{kHz}$ & $\begin{array}{l}\text { TS fuzzy- } \\
\text { based } \\
\text { Inc.Cond. }\end{array}$ & $\begin{array}{c}\text { Embedded } \\
\text { controller } \\
\text { dsPIC } 33 \mathrm{fJ} 128 \mathrm{M} \\
\mathrm{C} 802\end{array}$ & $\begin{array}{c}1 \mathrm{~W} \\
(2.5 \%)\end{array}$ & $97.5 \%$ & $2 \mathrm{~s}$ & $\$ 4.46$ \\
\hline \begin{tabular}{|l|}
$40](2014)$ \\
{$[28](2015)$}
\end{tabular} & $87 \mathrm{~W}$ & SEPIC & $20 \mathrm{kHz}$ & $\begin{array}{l}\text { Modified } \\
\text { Inc.Cond. }\end{array}$ & $\begin{array}{l}\text { Microcontroller } \\
\text { PIC18f4520 }\end{array}$ & $\begin{array}{c}1.5 \mathrm{~W} \\
(1.7 \%)\end{array}$ & $99 \%$ & $0.2 \mathrm{~s}$ & $\$ 4.26$ \\
\hline \begin{tabular}{|l|}
{$[41](2013)$} \\
\end{tabular} & $250 \mathrm{~W}$ & flyback & $40 \mathrm{kHz}$ & $\begin{array}{c}\text { PI- } \\
\text { Inc.Cond. }\end{array}$ & $\begin{array}{c}\text { Embedded } \\
\text { controller } \\
\text { dsPIC33FJ06GS } \\
202 \\
\end{array}$ & $\begin{array}{c}14 \mathrm{~W} \\
(5.6 \%)\end{array}$ & $97.2 \%$ & $5 \mathrm{~s}$ & $\$ 3.95$ \\
\hline Proposed & $120 W$ & Boost & $15 \mathrm{kHz}$ & $\begin{array}{c}\text { Modified } \\
\text { step-size } \\
\text { division- } \\
\text { free } \\
\text { Inc.Cond. }\end{array}$ & $\begin{array}{l}\text { Microcontroller } \\
\text { Atmega328 }\end{array}$ & $\begin{array}{c}4 \mathrm{~W} \\
(3.33 \%)\end{array}$ & $98.33 \%$ & $40 \mathrm{~ms}$ & $\$ 2.00$ \\
\hline
\end{tabular}

- : not mentioned, controller prices checked On-Line from $[42,43]$ at the submission time. 
The proposed MPPT technique, implemented by Atmega328 microcontroller, is compared with several experimental prototypes presented in most recent publications, as shown in Table III. Obviously, when compared with low-price microcontrollers' prototypes [21, 28, 40 and 41], the proposed algorithm gives faster MPPT during sudden changes. On the other hand, prototypes of faster response [9, 27, and 39] employ much more expensive microcontrollers than that applied in the proposed work. Moreover, the proposed prototype experiences one of the high tracking efficiencies of more than $98 \%$. In addition, it shows low steady-state power oscillations giving acceptable accuracy. Hence, being implemented by low-cost Atmega328 microcontroller, the proposed divisionfree algorithm, with the modified step-size, achieves the best compromise between MPPT dynamic response, steady-state performance and employed microcontroller cost. Consequently, its functionality is validated offering an economical efficient solution for stand-alone PV MPPT.

\section{Partial shading assessment}

This section investigates the performance of the proposed Incremental Conductance MPPT algorithm under partial shading operating condition. Moreover, a comparison between the conventional and modified proposed Incremental Conductance MPPT algorithms is carried in this section under partial shading conditions.

To test the modified Inc.Cond. MPPT technique, under partial shading conditions, two KD135SX_UPU PV modules are connected in series with a bypass diode connected in shunt with each module as illustrated in Fig. 12(a). First, both modules operate at normal conditions (at $1000 \mathrm{~W} / \mathrm{m}^{2}, 25^{\circ} \mathrm{C}$ ), then at $\mathrm{t}=0.3 \mathrm{~s}$, one module is partially shaded (working at $700 \mathrm{~W} / \mathrm{m}$ ).

Ideally, in the first case the total maximum PV power is $270 \mathrm{~W}$, while during partial shading; maximum PV power is reduced to 200W. When comparing the conventional and modified MPPT techniques during the previous conditions, the following performance results;

- As shown in Fig. 12(d), the conventional MPPT technique shows high steady-state power oscillations with tracking efficiency of $96 \%$ and $90.5 \%$ during normal and partial shading conditions respectively. Moreover, during the change, settling time is about $0.2 \mathrm{~s}$ and the PV power under-shoot is almost $18.5 \%$.

- $\quad$ On the other hand, in Fig. 12(e), the modified MPPT technique shows faster response with settling time of $0.1 \mathrm{~s}$ and reduced PV power under-shoot of $6.6 \%$. Moreover, it almost eliminates steady-state PV power oscillations showing more accurate results and higher tracked PV power. This results in much enhanced tracking efficiency of $99.7 \%$ and $94.3 \%$ during normal and partial shading conditions respectively.

Hence, the modified division-free Inc.cond. MPPT technique, adopting the proposed variable step-size, shows enhanced steadystate and transient response during partial shading conditions when compared to the conventional variable-step division-included Inc.Cond. technique. 


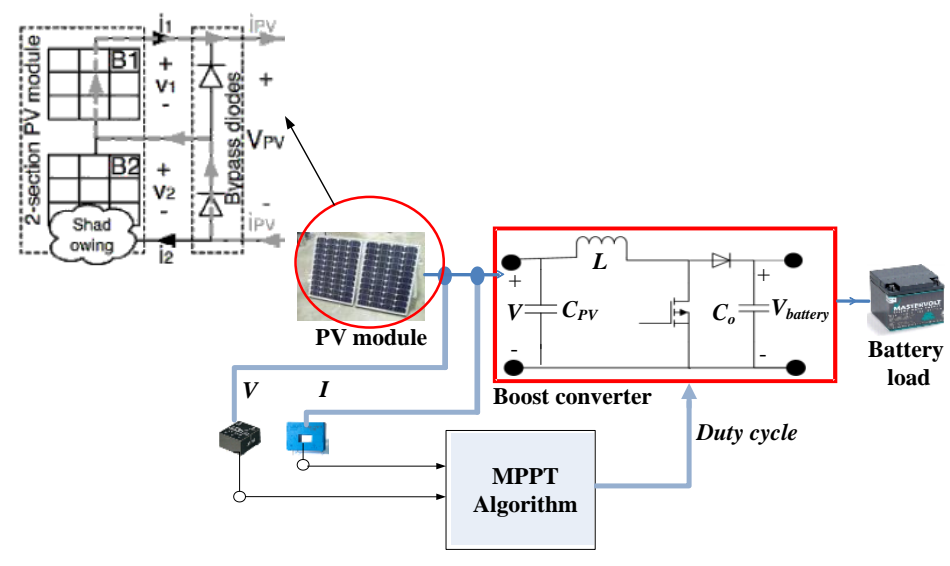

(a)

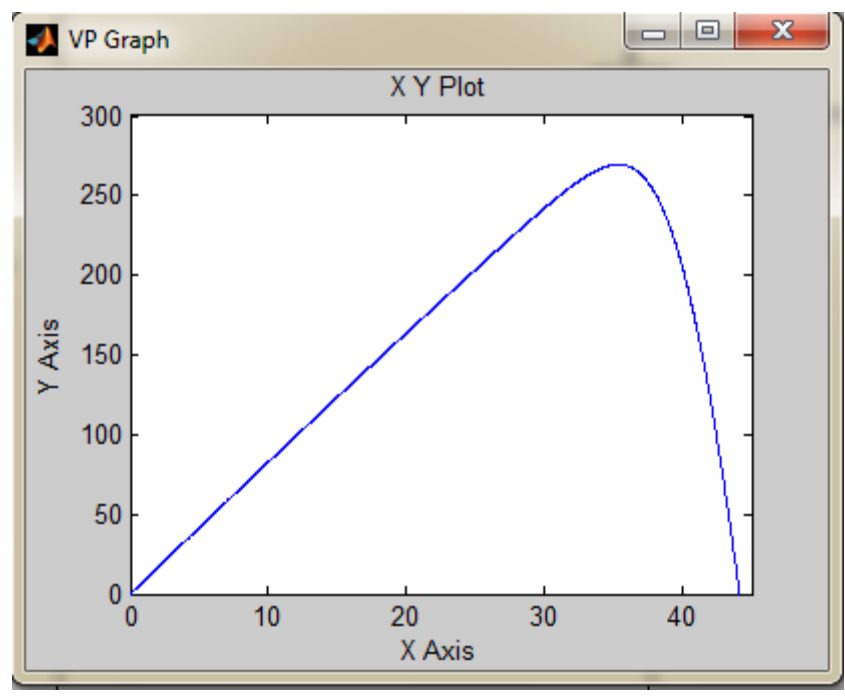

(b)

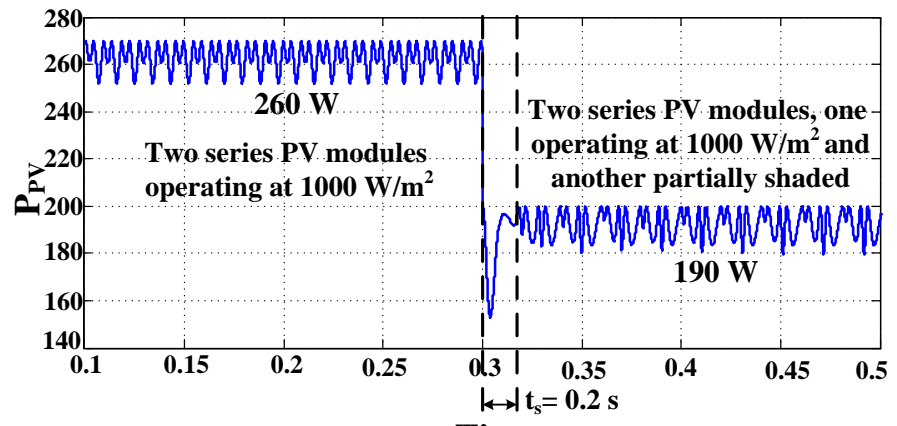

Time

(d)

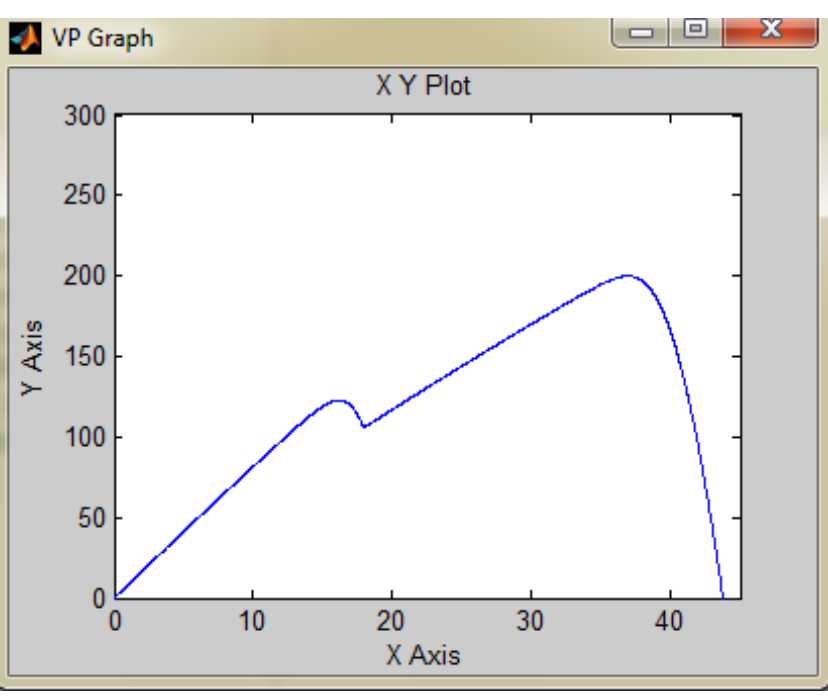

(c)

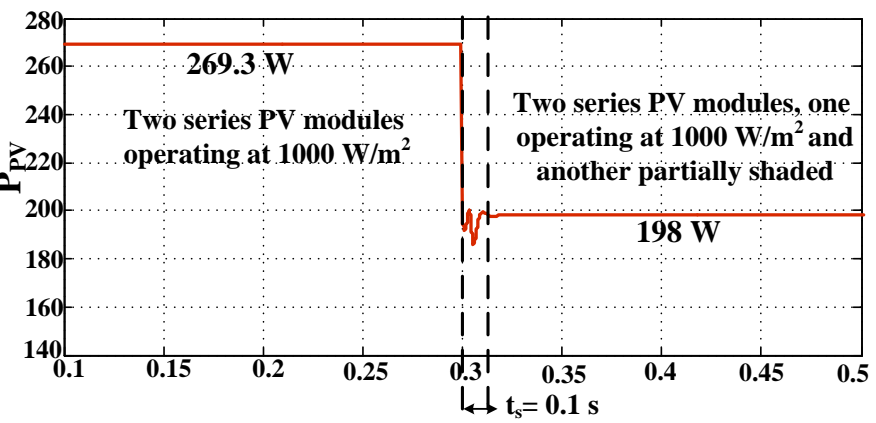

Time

Fig. 12: assessment of proposed IncCond. MPPT algorithm under partial shading:

(a) system block diagram, (b) P-V characteristics under uniform irradiance, (c) P-V characteristics under partial shading, (e) output PV power under sudden partial shading using conventional IncCond. MPPT, and (f) output PV power under sudden partial shading using proposed IncCond. MPPT 


\section{Conclusion}

In this paper, a low-cost variable-step MPPT technique is proposed based on Inc.Cond. algorithm. The modified algorithm features full elimination of the involved division computations, which simplifies its structure and reduces the required real processing time, thus facilitating algorithm implementation by low-cost microcontrollers in order to cut down system costs. Furthermore, the proposed associated variable step, being solely dependent on PV power change, shows minimal steady-state power oscillations around the MPP in addition to improved transient performance under sudden changes. The effectiveness of the proposed technique is verified by simulation and experimental results.

\section{Appendix}

TABLE IV. KD135SX_UPU MODULE SPECIFICATIONS AT $25^{\circ} \mathrm{C}, 1000 \mathrm{~W} / \mathrm{m}^{2}$

\begin{tabular}{|l|c|c|}
\hline Nominal Short Circuit Current $\left(I_{S C n}\right)$ & 8.37 & $\mathrm{~A}$ \\
\hline Nominal Open Circuit Voltage $\left(V_{O C n}\right)$ & 22.1 & $\mathrm{~V}$ \\
\hline Maximum Power Current $\left(I_{M P P}\right)$ & 7.63 & $\mathrm{~A}$ \\
\hline Maximum Power Voltage $\left(V_{M P P}\right)$ & 17.7 & $\mathrm{~V}$ \\
\hline Maximum Output Power $\left(P_{\max }\right)$ & 135 & $\mathrm{~W}$ \\
\hline Current /Temp. Coefficient $\left(K_{i}\right)$ & $5.02 \mathrm{e}^{-3}$ & $\mathrm{~A} /{ }^{\circ} \mathrm{C}$ \\
\hline Voltage/Temp. Coefficient $\left(K_{v}\right)$ & $-8 \mathrm{e}^{-2}$ & $\mathrm{~V} /{ }^{\circ} \mathrm{C}$ \\
\hline Series Cells & 36 & ---- \\
\hline
\end{tabular}




\section{References}

[1] B. K. Bose, "Global energy scenario and impact of power electronics in 21st century", IEEE Trans. Industrial Electronics, vol. 60, no. 7, pp. 26382651, July 2013

[2] J. M. Guerrero, F. Blaabjerg, T. Zhelev, K. Hemmes, E. Monmasson, S. Jemei, M.P. Comech, R. Granadino, and J.I. Frau, "Distributed generation: Toward a new energy paradigm", IEEE Industrial Electronics Magazine, vol. 4, no.1, pp.52-64, March 2010.

[3] M. Hosenuzzaman, N. A. Rahim, J. Selvaraj, M. Hasanuzzaman, A. B. M. A. Malek, and A.Nahar, "Global prospects, progress, policies, and environmental impact of solar photovoltaic power generation", Renewable and Sustainable Energy Reviews, vol. 47, no. 41, 2015, pp. 284-297

[4] M. Liserre, T. Sauter, and J. Y. Hung, "Future energy systems: Integrating renewable energy sources into the smart power grid through industrial electronics", IEEE Industrial Electronics Magazine, vol. 4, no.1, pp.18-37, March 2010.

[5] D.P. Hohm and M. E. Ropp, "Comparative study of maximum power point tracking algorithms", Progress in Photovoltaics: Research and Applications, vol. 11, no.1, 2003, pp. 47-62.

[6] S. Jain, and V. Agarwal, "Comparison of the performance of maximum power point tracking schemes applied to single-stage grid-connected photovoltaic systems," IET Electric Power Applications, vol. 1, no. 5, pp. 753-762, Sept. 2007

[7] T. Esram, P.L. Chapman, "Comparison of photovoltaic array maximum power point tracking techniques," IEEE Trans. Energy Conversion, vol. 22, no. 2, pp. 439-449, June 2007.

[8] B. Subudhi, and R. Pradhan, "A Comparative study on maximum power point tracking techniques for photovoltaic power systems", IEEE Trans. Sustainable Energy, vol. 4, no. 1, pp. 89-98, Jan. 2013.

[9] M. A. Gomes de Brito, L. Galotto, Jr., L. P. Sampaio, G. e Melo, and C. A. Canesin, "Evaluation of the main MPPT techniques for photovoltaic applications", IEEE Trans. Industrial Electronics, vol. 60, no. 3, pp. 1156-1167, March 2013.

[10] D. Sera, L. Mathe, T. Kerekes, S. V. Spataru, and R. Teodorescu, " On the perturb-and-observe and incremental conductance MPPT methods for PV systems", IEEE Journal of Photovoltaics, vol. 3, no. 3, pp. 1070- 1078, July 2013,

[11] V. M. Pacheco, L. C. Freitas, J. B. Vieira Jr., E. A. A. Coelho, and V. J. Farias, "Stand-alone photovoltaic energy storage system with maximum power point tracking", in Proc. IEEE Applied Power Electronics Conf. (APEC), 2003 , pp. 97 - 102.

[12] A. Ingegnoli, and A. Iannopollo, "A maximum power point tracking algorithm for stand-alone photovoltaic systems controlled by low computational power devices," in Proc. IEEE Mediterranean Electro technical Conf. (MELECON), 2010, pp.1522 - 1527.

[13] H. Aghazadeh, H. M. Kojabadi, and A. S. Yazdankhah, "Stand-alone PV generation system with maximum power point tracking", in Proc. Environment and Electrical Engineering conf., 2010, pp. 549 - 552

[14] M. A. Elgendy, B. Zahawi, and D. J. Atkinson, "Assessment of perturb and observe MPPT algorithm implementation techniques for PV pumping applications", IEEE Trans. Sustainable Energy, vol. 3, no. 1, pp. 21-33, Jan. 2012.

[15] R. Faranda, and S. Leva, "Energy comparison of MPPT techniques for PV systems", WSEAS Trans. Power Systems, vol. 3, Issue 6, pp 446-455, June 2008.

[16] S. Qin, M. Wang, T. Chen, and X. Yao, "Comparative analysis of incremental conductance and perturb-and-observation methods to implement MPPT in photovoltaic system," in Proc. IEEE Electrical and Control Engineering Conf. (ICECE), pp. 5792-5795, Sept. 2011.

[17] G.M.S. Azevedo, M.C. Cavalcanti, K.C. Oliveira, F. A.S. Neves and Z.D. Lins, "Evaluation of maximum power point tracking methods for grid connected photovoltaic systems", in Proc. IEEE Power Electronics Specialists Conf., 2008, pp 1456-1462.

[18] G. Spiazzi, S. Buso, P. Mattavelli, and P. Tenti, "Low complexity MPPT techniques for PV module converters," in Proc. IEEE Power Electronics Conf., pp.2074-2081, June 2010.

[19] X. Zhang, L. Zha, F. Liu, L. Tao, and W. Chen, "The analysis of power loss caused by the truncation error of MPPT algorithms," IEEE Symposium on Power Electronics for Distributed Generation Systems (PEDG), pp.7-11, June 2010

[20] M. Adly, M. Ibrahim, and H. El Sherif, "Comparative study of improved energy generation maximization techniques for photovoltaic systems," in Proc. IEEE Asia-Pacific Power and Energy Engineering Conf. (APPEEC), pp. 1-5, March 2012.

[21] P. C. Sekhar, and S. Mishra, "Takagi-Sugeno fuzzy-based incremental conductance algorithm for maximum power point tracking of a photovoltaic generating system", IET Renew. Power Gener., vol. 8, no. 8, 2014, pp. 900-914.

[22] B. Liu, S. Duan, F. Liu, and P. Xu, "Analysis and improvement of maximum power point tracking algorithm based on incremental conductance method for photovoltaic array", in Proc. IEEE Power Electronics and Drive Systems Conf., 2007, pp. 637-641

[23] F. Liu, S. Duan, F. Liu, B. Liu, and Y. Kang, "A variable step size INC MPPT method for PV systems," IEEE Trans. Industrial Electronics, vol.55, no.7, pp. 2622-2628, July 2008.

[24] D. Menniti, A. Burgio, N. Sorrentino, A. Pinnarelli, and G. Brusco, "An incremental conductance method with variable step size for MPPT: Design and implementation," in Proc. Electrical Power Quality and Utilization Conf. (EPQU), pp.1-5, Sept. 2009.

[25] Q. Mei, M. Shan, L. Liu, and J. M. Guerrero, "A novel improved variable step-size incremental-resistance MPPT method for PV systems," IEEE Trans. Industrial Electronics, vol. 58, no . 6, pp. 2427-2434, June 2011

[26] M. A. Elgendy, B. Zahawi, and D. J. Atkinson, "Assessment of the incremental conductance maximum power point tracking algorithm," IEEE Trans. on Sustainable Energy, vol. 4, no. 1, pp. 108- 117, Jan. 2013

[27] R. Faraji, A. Rouholamini, H. R. Naji, R. Fadaeinedjad, M. R. Chavoshian, "FPGA-based real time incremental conductance maximum power point tracking controller for photovoltaic systems, "IET Power Electron., vol. 7, no. 5, 2014, pp. 1294-1304.

[28] T. K. Soon and S. Mekhilef, "A fast-converging MPPT technique for photovoltaic system under fast-varying solar irradiation and load resistance," IEEE Trans. Industrial Informatics, vol. 11, no. 1, pp. 176-186, Feb. 2015.

[29] A. N. Ridge, G. A. J. Amaratunga, "Photovoltaic maximum power point tracking for mobile applications," Electronics Letters, vol.46, no.22, pp.15201521, Oct. 2010

[30] W. Ping, D. Hui, D. Changyu, and Q. Shengbiao, "An improved MPPT algorithm based on traditional incremental conductance method," in Proc. IEEE Power Electronics Systems and Applications Conf. (PESA), June 2011.

[31] Marcelo Gradella Villalva, Jonas Rafael Gazoli, and Ernesto Ruppert Filho, "Comprehensive approach to modeling and Simulation of Photo-voltaic Arrays", IEEE Trans. Power Electronics, vol. 24, no. 5, May 2009, pp.1198-1208. 
[32] D.W. Hart, Power Electronics Handbook. McGraw Hill, New York, 2011.

[33] A.K. Mukerjee and Nivedita Dasgupta, "DC power supply used as photovoltaic simulator for testing MPPT algorithms," Renewable Energy, vol. 32, pp. 587-592, April 2006.

[34] K. Ishaque, Z. Salam, M. Amjad, and S. Mekhilef, "An improved particle swarm optimization (PSO)-based MPPT for PV with reduced steady-state oscillation", IEEE Trans. Power Electronics, vol. 27, no. 8, August 2012, pp. 3627- 3638.

[35] F. Paz, and M. Ordonez,"Zero oscillation and irradiance slope tracking for photovoltaic MPPT", IEEE Trans. Industrial Electronics, vol. 61, no. 11, Nov. 2014, pp. 6138- 6147.

[36] Y. Jiang, J. Abu Qahouq, T. Haskew, "Adaptive-step-size with adaptive-perturbation-frequency digital MPPT controller for a single-sensor photovoltaic solar system", IEEE Trans. Power Electronics, vol. 28, no. 99, pp. 3195-3205, 2011.

[37] A. K. Abdelsalam, A. M. Massoud, S. Ahmed, and P. N. Enjeti, "High-performance adaptive perturb and observe MPPT technique for photovoltaicbased micro grids," IEEE Trans Power Electronics, vol. 26, no. 4, April 2011, pp. 1010-1021.

[38] A. Al Nabulsi, R. Dhaouadi, "Efficiency optimization of a DSP-based standalone PV system using fuzzy logic and dual-MPPT control", IEEE Trans. Ind. Inf., vol. 8, no. 3, pp. 573-584, 2012.

[39] M. M. Zainuri1, M. M. Radzi1, A. C. Soh1, N. Abd Rahim, "Development of adaptive perturb and observe-fuzzy control maximum power point tracking for photovoltaic boost dc-dc converter", IET Renew. Power Gener., vol. 8, no. 2, pp. 183-194, 2014.

[40] K. S. Tey, and S. Mekhilef, "Modified incremental conductance MPPT algorithm to mitigate inaccurate responses under fast-changing solar irradiation level," Solar Energy, vol.101, pp. 333-342, 2014.

[41] G. C. Hsieh, H. I. Hsieh, C. Y. Tsai, C. H. Wang; "Photovoltaic power-increment-aided incremental-conductance MPPT with two-phased tracking", IEEE Trans. Power Electron., vol. 28, no. 6, pp. 2895-2911, 2013

[42] Website: www.farnell.com

[43] Website: www.parts.arrow.com 